\title{
Flux Based Sensorless Speed Sensing and Real and Reactive Power Flow Control with Look-up Table based Maximum Power Point Tracking Technique for Grid Connected Doubly Fed Induction Generator
}

\author{
DVN. Ananth ${ }^{1}$, GV. Nagesh Kumar ${ }^{2}$ \\ ${ }^{1}$ Department of EEE, Viswanadha Institute of Technology and Management, Visakhapatnam, \\ 531173, India \\ ${ }^{2}$ Department of EEE, GITAM University, Visakhapatnam, 530045, Andhra Pradesh, India \\ email: drgvnk14@gmail.com
}

\begin{abstract}
This aim of this paper is to design controller for Doubly Fed Induction Generator (DFIG) converters and MPPT for turbine and a sensor-less rotor speed estimation to maintain equilibrium in rotor speed, generator torque, and stator and rotor voltages. It is also aimed to meet desired reference real and reactive power during the turbulences like sudden change in reactive power or voltage with concurrently changing wind speed. The turbine blade angle changes with variations in wind speed and direction of wind flow and improves the coefficient of power extracted from turbine using MPPT. Rotor side converter (RSC) helps to achieve optimal real and reactive power from generator, which keeps rotor to rotate at optimal speed and to vary current flow from rotor and stator terminals. Rotor speed is estimated using stator and rotor flux estimation algorithm. Parameters like tip speed ratio; coefficient of power, stator and rotor voltage, current, real, reactive power; rotor speed and electromagnetic torque are studied using MATLAB simulation. The performance of DFIG is compared when there is in wind speed change only; alter in reactive power and variation in grid voltage individually along with variation in wind speed.
\end{abstract}

Keywords: doubly fed induction generator (DFIG), maximum power point tracking (MPPT), real and reactive power control, rotor \& grid side converter (RSC \& GSC), sensor-less speed estimation, wind energy conversion system (WECS)

\section{Introduction}

Wind and solar electric power generation systems are popular renewable energy resources and are getting significance due to retreating of primary fuels and because of ecofriendly nature and is available from few kilo-watt power to megawatt rating [1]. The DFIG is getting importance compared to permanent magnet synchronous generator (PMSG) or asynchronous generator because of the operation under variable speed conditions [3]-[5], capability to extract more or maximum power point tracking theorm (MPPT) [2] and fast and accurate control of reactive power [6]-[13], better capability in low voltage and high voltage fault ride through situation, low cost of converters [14], effective performance during unbalanced and flickering loads. The efficiency enhancement and capability to meet desired reactive power demand from grid can be obtained by adopting robust rotor side control (RSC) for DFIG. But in general, RSC is rated from $25 \%$ to $35 \%$ of generator stator rating, which allows only $\pm 25 \%$ variation in rotor speed. However, due to low power rating of converters, the cost incurred on controllers is low.

In general, the stator and rotor windings of DFIG can deliver both real and reactive power to the grid. The direction of real and reactive power flow from rotor can me varied to meet the desired reactive power requirements from grid with the help of sophisticated RSC controller scheme. The MPPT algorithm will be designed mostly for wind turbines to extract more mechanical power by adjusting the rotor blades and to make the generator shaft to rotate at optimal speed. This algorithm makes the blades to sweep maximum area to make wind sweeping turbine shaft with more mechanical force so that maximum mechanical power can be achieved at that particular wind speed. However more mechanical power can be obtained naturally at higher wind speed from the wind turbine. 
The increase in wind generators connected to grid leads to penetration issues causes many problems to sensitive generators. If any generators among them are unable to convene desired grid codes, make them to trip, causing voltage at point of common coupling (PCC) decreases tending the other generators to oscillate if any small disturbance like change in wind speed occurs. It will tend WECS system to weaken or work at marginal stable situation for certain time. The solution to above penetration issue for making healthy system is effective control of reactive power.

To achieve desired reactive power requirement for grid, rotor side converter (RSC) plays a vital role in coordination with grid side controller (GSC). With change in grid voltage (due to reason like faults or so) stator voltage also needs to be adopted for not loosing synchronism with grid and to maintain stability, GSC controller is necessary. Maximum power extraction from DFIG using pitch angle controller and optimal power coefficient at low and high speed is analyzed in [15]. Direct and indirect control of reactive power control with an aim to meet active and reactive power equal to the reference values as achieved in [16]. MPPT based WECs design facilitates the wind turbine has to operate in variable speed as per the ideal cube law power curve [17]-[21]. The constant power mode of operation can be achieved by (i) including energy storage devices [21]-[25] and (ii) employing pitch control [17],[26],[27]. Introduction to tuning of PID controllers [28], pitch angle control with neural network for optimal tracking of real power is given in [29]. Advanced techniques like hybrid fuzzy sliding mode [29] and growing natural gas based MPPT algorithm is proposed in [30]. These advanced methods can improve overall DFIG system performance with robust control, faster in action and enhanced tracking of real and reactive power.

In this paper, performance of DFIG was compared and analyzed under situations like, with variation in wind speed alone, with reactive power variation and with grid voltage variation for same variation in wind speed. In these cases, variation in tip speed ratio and coefficient of turbine power, effect on real and reactive power flows, voltages and current from stator and rotor, rotor speed and electromagnetic torque are examined. The paper was organized with overview of WECS with wind turbine modeling and pitch angle controller in 2 nd section, study of mathematical modeling of DFIG in 3rd section, the 4th section describe RSC architecture and design; section 5 analyses the performance of DFIG for three cases like effect of variation on wind speed variation, reactive power demand along with variation in wind speed and grid voltage variation with wind speed. Conclusion was given in Section 6. System parameters are given in appendix.

\section{Wind Energy Conversion System (WECS)}

The overview of wind energy conversion system (WECS) is shown in Figure 1. The construction has following dynamic models: Wind speed calculator is an anemometer sensor system with storage system to measure the actual wind speed in meters per second at that instant with air density and ambient temperature measurements also, and is given to WECS and turbine system. The WECS system consists of aerodynamics and wind turbine control model to extract maximum power during steady state and protection during transient or unstable state of operation. Mechanical and electrical model control system is to generate reference speed, power and voltage signals for controlling real and reactive power flow from generator to the grid and also contains protective system during abnormal situation. The mechanical model system gives command to turbine for extraction of maximum mechanical power extraction for a given wind speed and the electrical model system give command for the generator to produce respective real power and reactive power and to maintain synchronism under all operating condition.

The real and reactive power from DFIG is controlled by using two controllers namely rotor side (RSC) and grid side (GSC) controller using converter controller model as shown in Figure 2. The converter model is a bidirectional switches with IGBT (integrated bi-polar transistor), which controls the voltage, real and reactive power from stator and rotor to grid. 


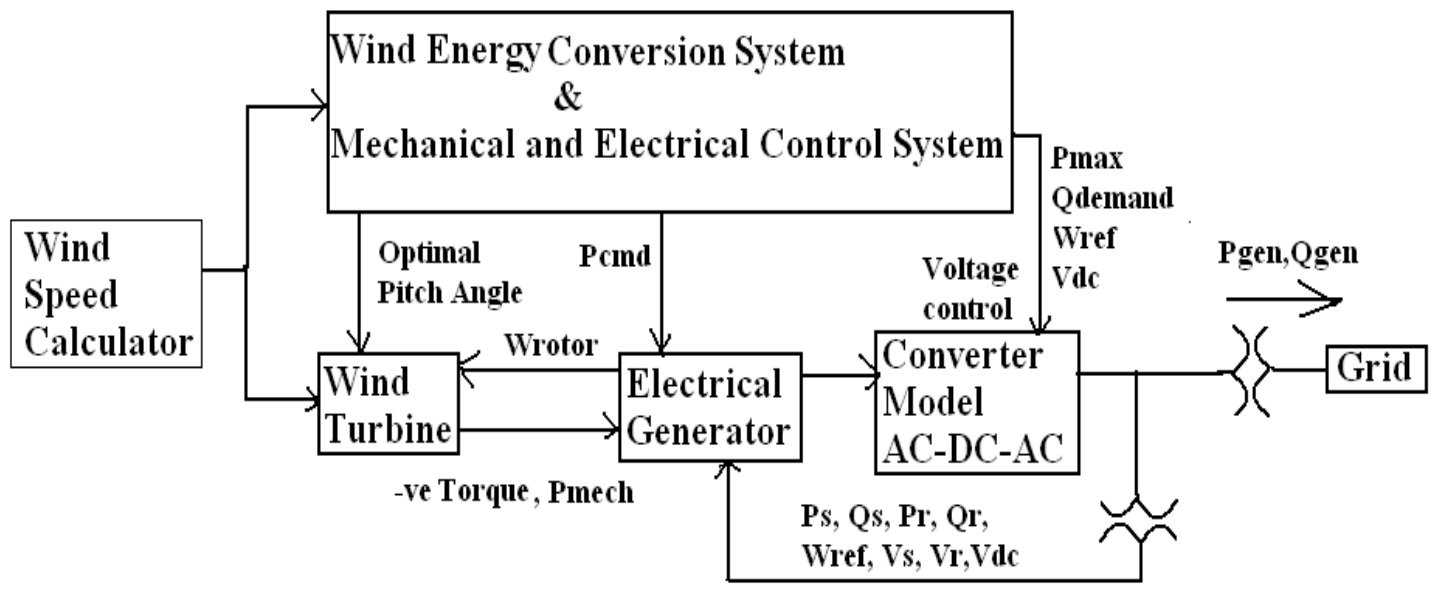

Figure 1. Block diagram of WECS for grid connected DFIG

The RSC controller aim is to maintain DFIG rotor to maintain optimal speed specified by MPPT and also to control the reactive power flow by varying rotor current direction. The GSC controller is maintain constant DC link voltage at back to back terminals across capacitor, so that this voltage can be maintained as per PCC point and also for rapid supply of leading or lagging reactive power without much deviation from generator real power.

The transformer near the grid is a step-up voltage and the other transformer is an isolation transformer.

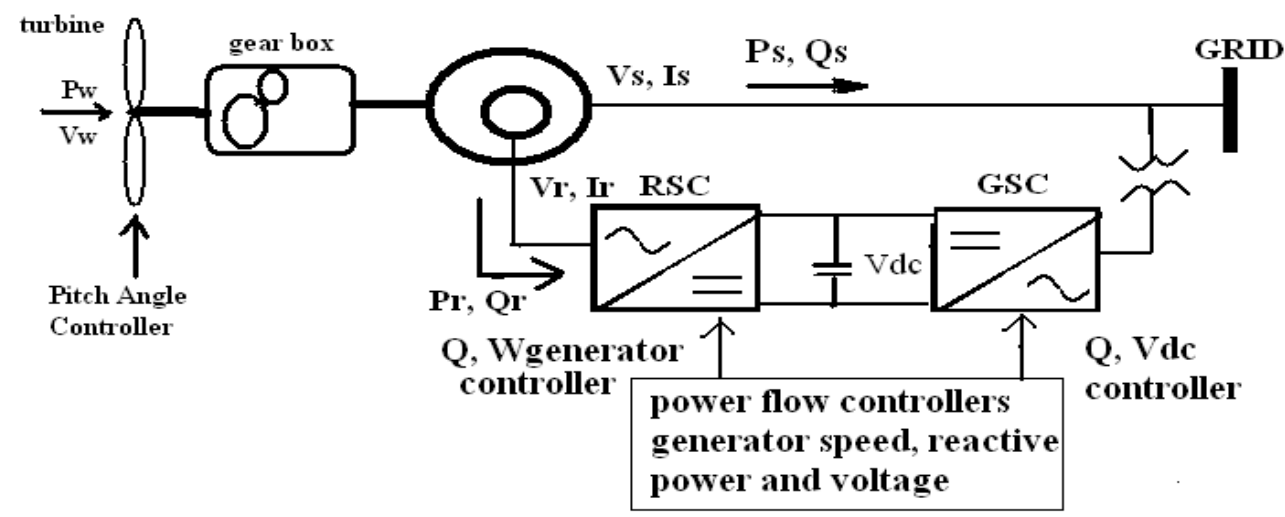

Figure 2. Schematic diagram of WECS for DFIG system connected to grid

\subsection{The wind turbine modeling}

The wind turbine is the prime mover which facilitates in converting kinetic energy of wind into mechanical energy which further converted into electrical energy. From basic theory of wind energy conversion, the output mechanical power from turbine is given by

$$
P_{\text {mech }}=\frac{1}{2} C p(\lambda, \beta) \rho \pi r^{2} v_{\omega}^{3}
$$

Where $\mathrm{P}_{\text {mech }}$ is the mechanical power output from wind turbine, $\mathrm{Cp}$ is coefficient of wind power as a function of pitch angle $(\beta)$ and tip speed ratio $(\lambda), \rho$ is specific density of air, $r$ is radius of wind turbine blade, $v_{\omega}$ is wind speed.

$$
\operatorname{Cp}(\lambda, \beta)=0.5176\left(\frac{116}{\lambda_{i}}-0.4 \beta-5\right) e^{-21 / \lambda_{i}+0.0068 \lambda}
$$


The tip sped ratio is a relation between turbine speed $\left(\omega_{t}\right)$, radius of turbine blades and wind speed and tip speed ratio at particular angle ' $i$ ' is given the relation as shown below

$$
\lambda=\frac{\omega_{\mathrm{t}} \mathrm{r}}{v_{\omega}} \text { and } \frac{1}{\lambda_{\mathrm{i}}}=\frac{1}{\lambda+0.08 \beta}-\frac{0.035}{\beta^{3}+1}
$$

the output power at nominal wind speed is given by the below equation

$$
v_{n}=\sqrt[3]{\frac{2 P_{s h}}{\pi \rho r^{3} C_{p \max }}}
$$

Where Psh is the turbine shaft power and Cpmax is maximum mechanical power coefficient. The maximum power $\mathrm{P}_{\max }$ from wind turbine can be extracted by using the equation

$$
\mathrm{P}_{\max }=\frac{1}{2 \lambda_{\mathrm{opt}}^{3}} \pi \rho \mathrm{C}_{\mathrm{pmax}} \mathrm{r}^{5} \omega_{\mathrm{opt}}^{3}
$$

\subsection{Pitch angle controller}

The wind turbine blade angles are controlled by using servo mechanism to maximize turbine output mechanical power during steady state and to protect the turbine during high wind speeds.

This control mechanism is known as pitch angle controller. When wind speed is at cut-in speed, the blade pitch angle is set to produce optimal power, at rated wind speed; it is set to produce rated output power from generator. At higher wind speeds, this angle increases and makes the turbine to protect from over-speeding. The pitch angle controller circuit is as shown in Figure 3.

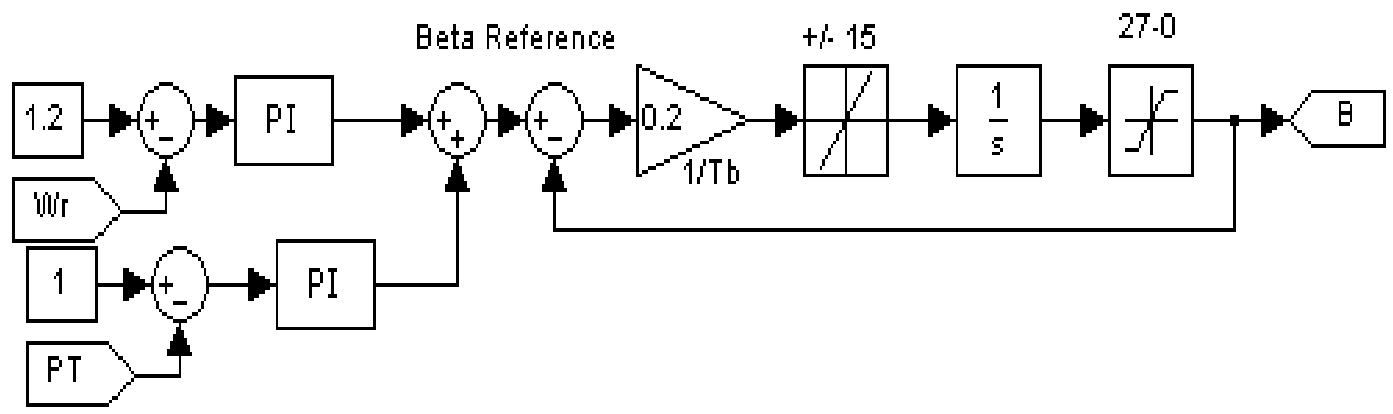

(a)

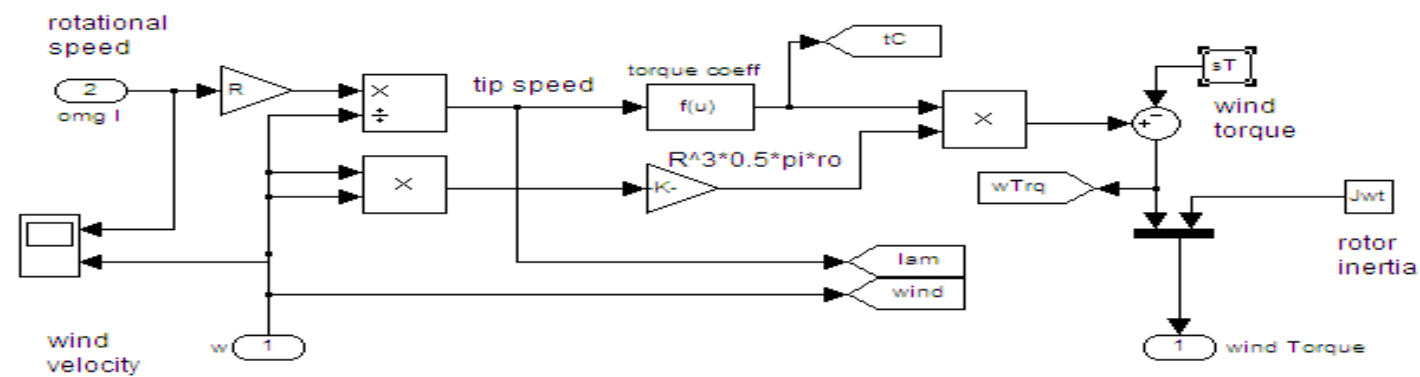

Aerodinamics modelling

(b)

Figure 3. The pitch angle controller circuit, a) Pitch angle controller design for wind turbine, b) Wind turbine modeling- mechanical torque derivation from wind speed, tip speed ratio and other characteristic parameters 
In this system reference generator speed is $\mathrm{W}_{\mathrm{r}}^{\mathrm{ref}}=1.2 \mathrm{p} . \mathrm{u}$ or is obtained from MPPT algorithm and actual speed of the generator is Wr. The actual speed can be estimated using an encoder or using sensor-less estimation strategy. The error between reference and actual values is controlled using $\mathrm{PI}$ controller. In the similar way, the difference in reference $\left(P^{*}=1\right)$ and actual power outputs from turbine (PT) is controlled by $\mathrm{PI}$ controller. Both the outputs from $\mathrm{PI}$ controller are designed to get reference pitch angle controller (Bref). The closed loop control of pitch angle is obtained as shown in Figure 3 . The optimal pitch angle is written mathematically at this point as $\int \frac{1}{\mathrm{~T}_{\beta}}\left(\beta_{\mathrm{ref}}-\beta\right) \mathrm{dt}$. If pitch angle is set at zero degrees, maximum power can be extracted from the turbine. In general pitch angle is set between 0 to $7.50 / \mathrm{s}$ to extract maximum power, also these values specifies the turbine is working in stable environment and if is set at 27o/s, it means either wind speed is high called cutout wind speeds or may be external fault in the external electric system. The reference real power $(\mathrm{Pe})$ or actual mechanical output from turbine and mechanical output torque ( $\mathrm{Tm}$ ) is shown in Figure 4. Using Tip Speed Ratio (TSR) and Coefficient of Power (CP) are used to generate reference power and the control scheme is useful to extract maximum mechanical power, thereby more mechanical tore Tm by using the MPPT algorithm.

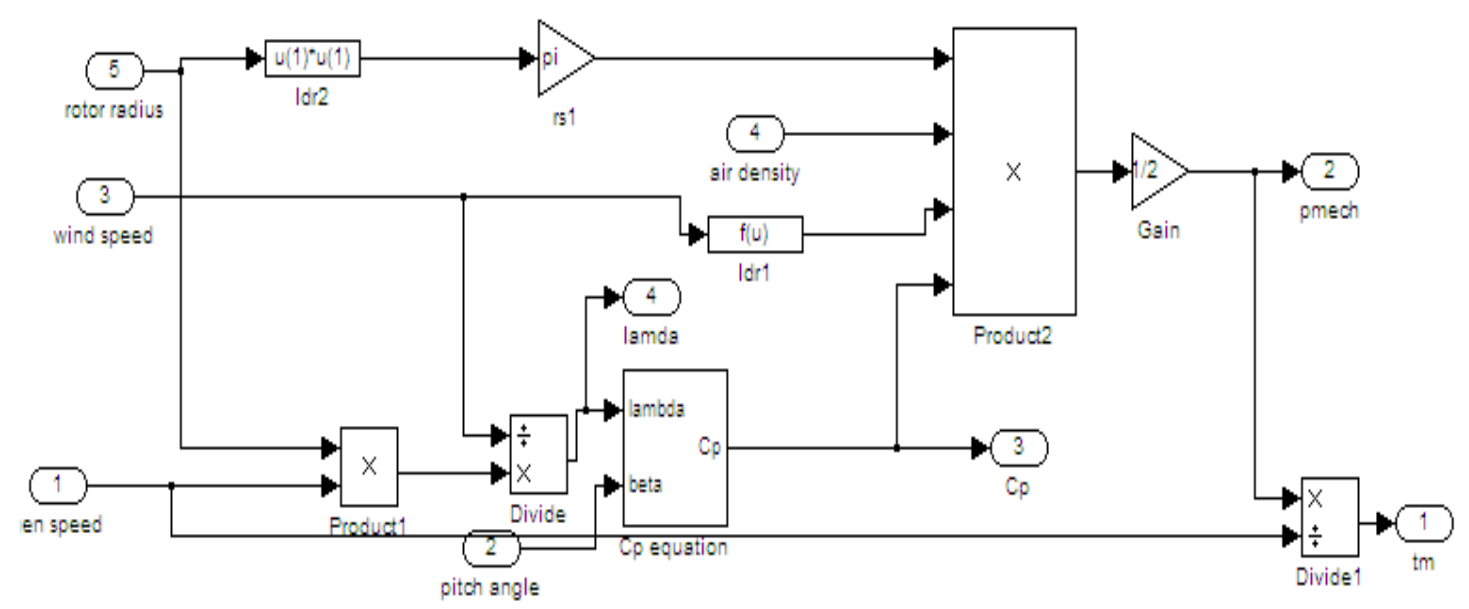

Figure 4. Reference electrical power generation control circuit and mechanical torque output from turbine with MPPT algorithm

The aim of MPPT algorithm as shown in Figure 4 is to generate optimal mechanical power output from turbine and mechanical input torque to be given to the doubly fed induction generator. The mechanical power is given as reference to grid side converter (GSC) to make the rotor to rotate at optimal speed. The optimal input torque to DFIG is so as to operate for extracting maximum power from the generator. The inputs to MPPT algorithm are radius of curvature 'R' of turbine wings, rotor speed (Wr), wind sped ( $\mathrm{Vw}$ ) and pitch angle (beta). Initially with $\mathrm{R}, \mathrm{Wr}$ and $\mathrm{Vw}$, tip speed ratio $(\mathrm{g})$ is determined. Later using equation 2 and input parameter beta, coefficient of power (Cp) is calculated. Based on equation 5 , optimal mechanical power (Pm_opt) is determined and dividing mechanical power by rotor speed, optimal torque (Tm_opt) is determined. The pitch angle (beta) is determined as shown in Figure 4. The application of Pm_opt and Tm_opt is shown in Figure 6 and 7.

When there is change in wind speed, turbine speed changes and thereby beta, Cp and mechanical power and torque changes [2]. If grid voltage varies due to fault or any conditions, the current flow in the rotor circuit varies. Huge requirement of reactive power for grid will come to picture to maintain low voltage ride through (LVRT) phenomenon. During this period, rotor speeds increases gradually and lose synchronism if not provided with LVRT capability [14]. In general, load varies continuously. So, active and reactive power demand from grid changes considerably. It has to be provided by DFIG. For this enhanced real and reactive power is necessary [12]. For this optimal real power generation is achieved by extracting 
optimal mechanical power output from turbine is derived and made to run at optimal loading and speed. For this MPPT algorithm proposed will be very helpful.

\subsection{Mathematical Modeling of DFIG}

There are many advantages of DFIG compared to squirrel cage induction generator or permanent magnet synchronous generator. Using DFIG independent control of active and reactive power, variable speed and constant frequency operation, over load capability, higher efficiency, higher ratings, are possible. The converters need to handle only $25 \%$ to $35 \%$ of generator capacity, thereby minimizing operating cost and switching losses, low hardware cost etc.

The equivalent circuit of DFIG in rotating reference frame at an arbitrary reference speed of $\omega$ is shown in Figure 5. The equations can be derived in dq reference frame were as follows:

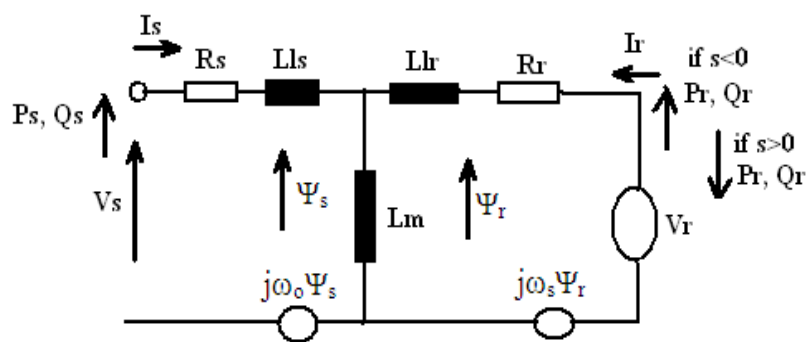

Figure 5. Equivalent circuit of DFIG in rotating reference frame at speed $\omega$

The stator direct and quadrature axis (dq) voltages and flux of DFIG can be written as

$$
\begin{aligned}
& V_{s d}=R_{s} I_{s d}-\omega_{s} \psi_{s q}+\frac{d \psi_{s d}}{d t} \\
& \psi_{s d}=\left(\left(V_{s d}-R_{s} I_{s d}\right) \frac{1}{s}-\sigma L_{s} I_{s d}\right) \frac{L_{r}}{L_{m}} \\
& V_{s q}=R_{s} I_{s q}+\omega_{s} \psi_{s d}+\frac{d \psi_{s q}}{d t} \\
& \psi_{s q}=\left(\left(V_{s q}-R_{s} I_{s q}\right) \frac{1}{s}-\sigma L_{s} I_{s q}\right) \frac{L_{r}}{L_{m}}
\end{aligned}
$$

The equations $6 b$ and $7 b$ are stator $d$ and $q$ axis flux written in terms of stator voltage, current and passive elements. The leakage factor $\sigma$ can be stated as $1-\frac{L_{m}^{2}}{L_{s} L_{r}}$.

The rotor direct and quadrature axis are derives as

$$
\begin{aligned}
& V_{r d}=R_{r} I_{r d}-\left(\omega_{s}-\omega_{r}\right) \psi_{r q}+\frac{d \psi_{r d}}{d t} \\
& V_{r q}=R_{r} I_{r q}+\left(\omega_{s}-\omega_{r}\right) \psi_{r d}+\frac{d \psi_{r q}}{d t}
\end{aligned}
$$

The difference between stator speed $\left(\omega_{\mathrm{s}}\right)$ and rotor speed $\left(\omega_{\mathrm{r}}\right)$ is known as slip speed $\left(s \omega_{s}\right)$. For motoring action, this difference is less than zero and for generating, the slip speed is negative. The stator and rotor flux linkages in axis frame are given below

$$
\begin{aligned}
& \psi_{s d}=L_{l s} I_{s d}+L_{m} I_{r d} \\
& \text { or } \psi_{s d}=L_{m} I_{s m} \\
& \psi_{s q}=L_{l s} I_{s q}+L_{m} I_{r q}
\end{aligned}
$$




$$
\begin{aligned}
& \psi_{\text {rd }}=L_{l r} I_{r d}+L_{m} I_{s d} \\
& \psi_{r q}=L_{l r} I_{r q}+L_{m} I_{s q}
\end{aligned}
$$

The magnitude of rotor flux can be written as $\psi_{\mathrm{r}}=\sqrt{\psi_{\mathrm{rd}}^{2}+\psi_{\mathrm{rq}}^{2}}$.

The stator real power in terms of two axis voltage and current is

$$
P_{s}=\frac{3}{2}\left(V_{s d} I_{s d}+V_{s q} I_{s q}\right)
$$

The rotor real power in terms of two axis voltage and current is

$$
\mathrm{P}_{\mathrm{r}}=\frac{3}{2}\left(\mathrm{~V}_{\mathrm{rd}} \mathrm{I}_{\mathrm{rd}}+\mathrm{V}_{\mathrm{rq}} \mathrm{I}_{\mathrm{rq}}\right)
$$

The stator reactive power in terms of two axis voltage and current is

$$
Q_{s}=\frac{3}{2}\left(V_{s q} I_{s d}-V_{s d} I_{s q}\right)
$$

The rotor reactive power in terms of two axis voltage and current is

$$
\mathrm{Q}_{\mathrm{r}}=\frac{3}{2}\left(\mathrm{~V}_{\mathrm{rq}} \mathrm{I}_{\mathrm{rd}}-\mathrm{V}_{\mathrm{rd}} \mathrm{I}_{\mathrm{rq}}\right)
$$

The quadrature and direct axis rotor current in terms of stator parameters can be written as

$$
\begin{aligned}
& I_{r q}=\frac{P_{s}}{\left|V_{s}\right|}=\frac{-L_{l s}}{L_{m}} I_{s q} \\
& I_{r d}=\frac{Q_{s}}{\left|V_{s}\right|}+\frac{\left|V_{s}\right|}{\omega_{s} L_{m}}
\end{aligned}
$$

The output electromagnetic torque is given by the equation

$$
\mathrm{T}_{\mathrm{e}}=\frac{3}{2} \rho \mathrm{L}_{\mathrm{m}}\left(\mathrm{I}_{\mathrm{sq}} \mathrm{I}_{\mathrm{rd}}-\mathrm{I}_{\mathrm{sd}} \mathrm{I}_{\mathrm{rq}}\right)
$$

The mechanical torque output from the turbine in terms of mechanical power and rotor speed is

$$
\mathrm{T}_{\mathrm{m}}=\frac{\mathrm{P}_{\mathrm{mech}}}{\omega_{\mathrm{r}}}
$$

\section{Rotor Side Controller (RSC) and Grid Side Controller (GSC) Architecture and Design}

\subsection{Operation of GSC and RSC controllers}

The rotor side converter (RSC) is used to control the speed of rotor and also helps in maintaining desired grid voltage as demanded. The control circuit for grid side controller (GSC) is shown in $6 a$ and rotor side controller (RSC) is shown in Figure 6b for the general network in Figure 8 with internal circuits for deriving RSC PLL for 2 phases to 3 phases inverse Parks transformation is shown in Figure 9. This Figure 9 helps to inject current in rotor winding at slip frequency. The GSC and RSC have four control loops each, later has one speed control loop, other is reactive power and last two are direct and quadrature axis current control loops. The speed and reactive power control loops are called outer control loop and direct and quadrature axis control loops are called inner control loops. The reference rotor speed is derived from the wind turbine optimal power output PmOpt as shown in Figure 4 and grid power demand. In total, the reference power input to the lookup table as shown in Figure $6 \mathrm{~b}$ is Pm,gOpt. Based on the 
value of $\mathrm{Pm}, \mathrm{gOpt}$, the rotor is made to rotate at optimal speed so as to extract maximum power from DFIG set. The difference between reference speed of generator and actual speed of generator is said to be rotor speed error. Speed error is minimized and maintained nearly at zero value by using speed controller loop which is a PI controller with Kpn and Kin as proportional and integral gain parameters. The output from speed controller is multiplied with stator flux (Fs) and ratio of stator and rotor ( $L s$ and $L r$ ) inductances to get reference quadrature current (Iqr) for rotor. The error in reference and actual reactive power give reference direct axis current (Iqr). The difference between these reference and actual two axis currents is controlled by tuned $\mathrm{Pl}$ controller to get respective direct and quadrature axis voltages. The output from each PI controller is manipulated with disturbance voltages to get reference voltage for pulse generation as shown in Figure $6 \mathrm{~b}$. It must be noted that the pulses are regulated at slip frequency for RSC rather than at fundamental frequency and slip frequency synchronizing for inverse Park's transformation can also be seen in the figure.

The MATLAB based block diagram of GSC is shown in Figure 6a. For a given wind speed, reference or control power from turbine is estimated using lookup table. From equation (15), stator real power (Pstator) is calculated and the error in powers is difference between these two powers $(\mathrm{dP})$ which is to be maintained near zero by $\mathrm{PI}$ controller. The output from PI controller is multiplied with real power constant $(\mathrm{Kp})$ gives actual controllable power after disturbance. The difference in square of reference voltage across capacitor dc link $\left(V_{d c}^{*}\right)$ and square of actual dc link voltage $(\mathrm{Vdc})$ is controlled using $\mathrm{PI}$ controller to get reference controllable real power. The error in the reference and actual controllable power is divided by using $2 / 3 \mathrm{Vsd}$ to get direct axis (d-axis) reference current near grid terminal (Igdref). Difference in Igdref and actual d-axis grid current is controlled by PI controller to get d-axis voltage. But to achieve better response during transient conditions, decoupling d-axis voltage is added as in case of separately excited DC motor. This decoupling term helps in controlling steady state error and fastens transient response of DFIG during low voltage ride through (LVRT) or during sudden changes in real or reactive powers from/ to the system.

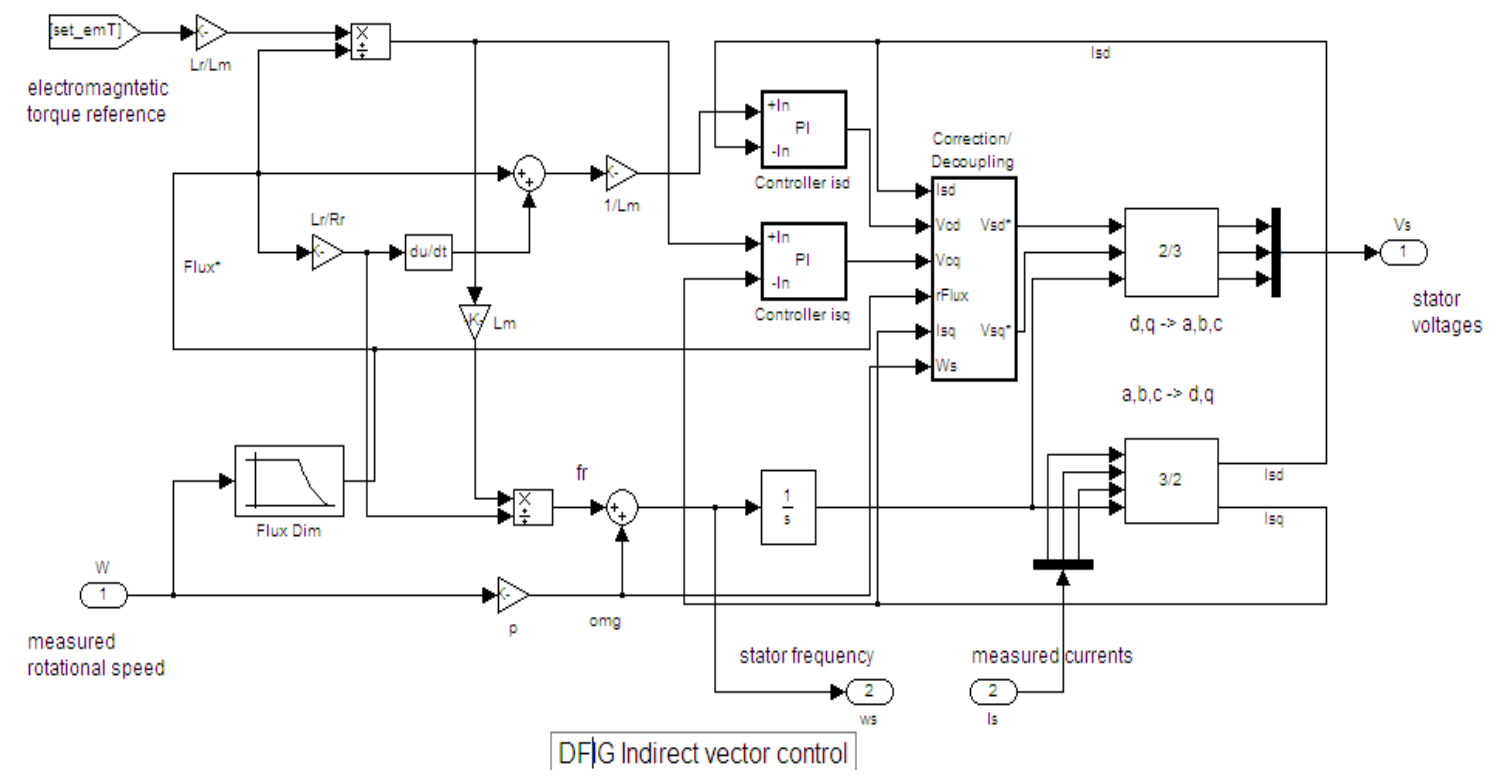

Figure 6a. Grid side controller with indirect vector control technique for DFIG 


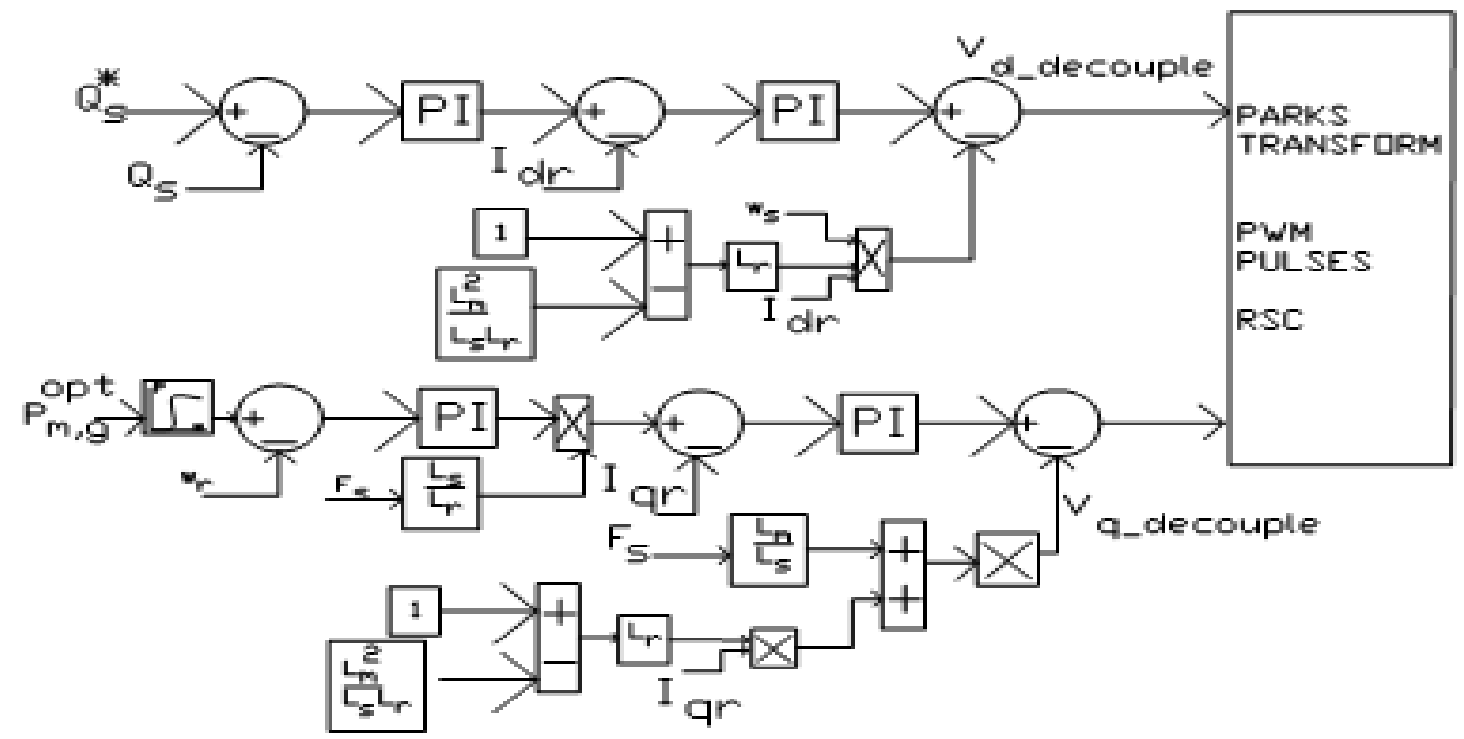

Figure $6 \mathrm{~b}$. Rotor side converter using power to speed conversion with improved vector control for DFIG

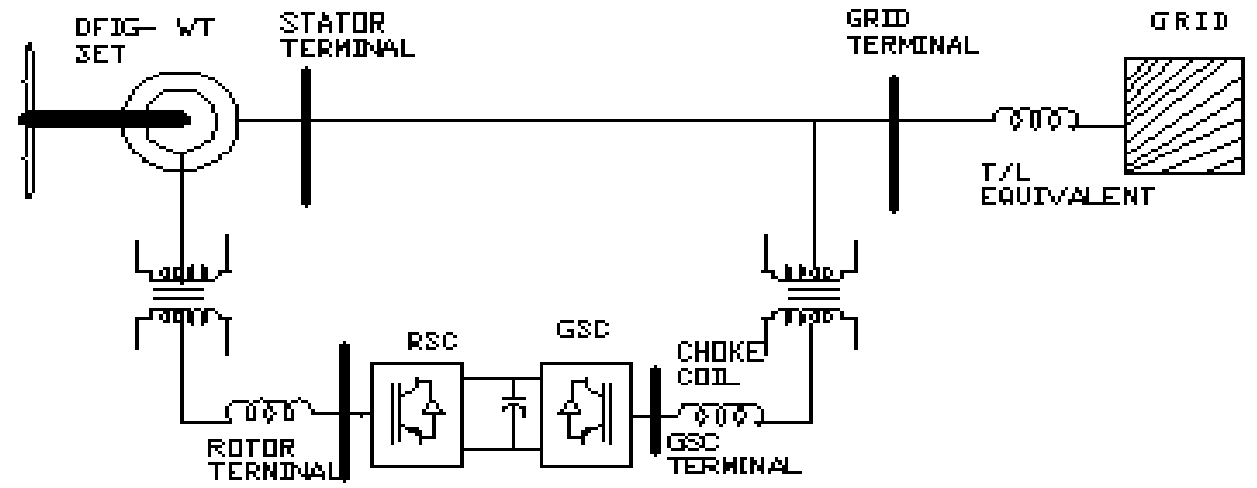

Figure 7. Design of overall DFIG based system with RSC and GSC

Similarly from stator RMS voltage (Vs) or reference reactive power, actual stator voltage or reactive power is subtracted by $\mathrm{PI}$ controller and multiplied with appropriate reactive power constant $(\mathrm{Kq})$ to get actual reference reactive power compensating parameter. From equation (17), actual reactive power is calculated and the difference in this and actual compensating reactive power and when divided by $2 / 3 \mathrm{Vsq}$, we get quadrature axis (q-axis) reference current (Iqref). When the difference in lqref and stator actual q-axis current (Iq) is controlled by PI controller, reference q-axis voltage is obtained. As said earlier, to improve transient response and to control steady state error, decoupled q-axis voltage has to be added as shown in Figure $6 a$. Both $d$ and $q$ axis voltage parameters so obtained are converted to three axis abc parameters by using inverse Park's transformation and reference voltage is given to scalar PWM controller to get pulses for grid side controller. 

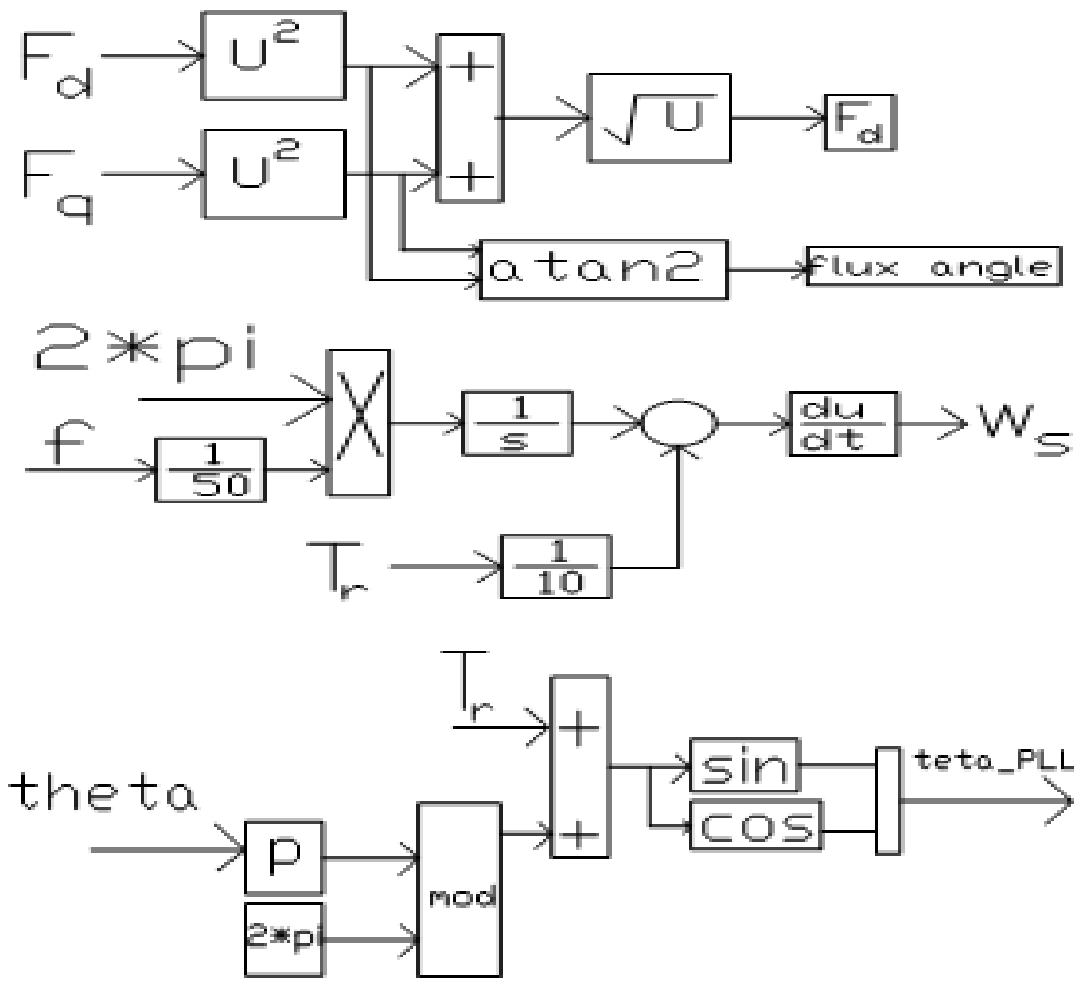

Figure 8. Internal circuits design of RSC for extracting rotor Parks transform PLL block for dq to abc conversion

The main purpose of rotor side controller (RSC) is to maintain desired generator speed and reactive power flow from rotor circuit, while grid side controller (GSC) is used to achieve nearly constant DC link voltage and to control bidirectional reactive power flow from GSC converter, stator and grid. This GSC is also capable in controlling real power from stator to achieve desired real power from generator stator.

The general form of speed regulation is given by

$$
\begin{aligned}
T_{e} & =J \frac{d \omega_{r}}{d t}+B \omega_{r}+T_{l} \\
& =(J s+B) \omega_{r}+T_{l}
\end{aligned}
$$

Where $T_{e}$ is electromagnetic torque, $\mathrm{J}$ is moment of inertia and $\mathrm{B}$ is friction coefficient, $\mathrm{T}_{1}$ is considered to be disturbance.

Multiplying both sides with $\omega_{\text {error }}$, we get the equation as

$\mathrm{T}_{\mathrm{e}} \omega_{\text {error }}=(\mathrm{Js}+\mathrm{B}) \omega_{\mathrm{r}} \omega_{\text {error }}+\mathrm{T}_{1} \omega_{\text {error }}$

Considering $\omega_{\mathrm{r}}$ constant and change in speed error is $\omega_{\text {error }}$ is control variable, the above equation becomes.

$$
\mathrm{P}_{\mathrm{s}}^{*}=\left(\mathrm{K}_{\mathrm{in}} \mathrm{s}+\mathrm{K}_{\mathrm{pn}}\right) \omega_{\text {error }}+\mathrm{P}_{\mathrm{l}}
$$

As product of torque and speed is power, we will be getting stator reference power and disturbance power as shown below.

$$
P_{s}^{*}-P_{1}=\left(K_{\text {in }} s+K_{p n}\right) \omega_{\text {error }}
$$

Where, $\mathrm{K}_{\mathrm{in}}=\mathrm{J}^{*} \omega_{\mathrm{r}}$ and $\mathrm{K}_{\mathrm{pn}}=\mathrm{B}^{*} \omega_{\mathrm{r}}$ 
Finally direct axis reference voltage can be written by using equation (26) and is incorporated for Figure 6a. The equations for voltage and current control loops are

$$
\begin{aligned}
& \mathrm{V}_{\mathrm{rd}}^{*}=-\left(\omega_{\mathrm{error}}\right)\left(\mathrm{K}_{\mathrm{pn}}+\frac{\mathrm{K}_{\mathrm{in}}}{\mathrm{s}}\right)+\left(\mathrm{P}_{\mathrm{s}}\right)\left(\mathrm{K}_{\mathrm{pt}}+\frac{\mathrm{K}_{\mathrm{it}}}{\mathrm{s}}\right) \\
& \mathrm{V}_{\mathrm{rq}}^{*}=\mathrm{Q}_{\mathrm{error}}\left(\mathrm{K}_{\mathrm{pQ}}+\frac{\mathrm{K}_{\mathrm{iQ}}}{\mathrm{s}}\right) \\
& \mathrm{V}_{\mathrm{gd}}^{*}=\mathrm{K}_{\mathrm{gp}}\left(\mathrm{i}_{\mathrm{gd}}^{*}-\mathrm{i}_{\mathrm{gd}}\right)+\mathrm{k}_{\mathrm{gi}} \int\left(\mathrm{i}_{\mathrm{gd}}^{*}-\mathrm{i}_{\mathrm{gd}}\right) \mathrm{dt}-\omega_{\mathrm{o}} \mathrm{L}_{\mathrm{g}} \mathrm{i}_{\mathrm{gd}}++\mathrm{k}_{1} \mathrm{~V}_{\mathrm{sd}} \\
& \mathrm{V}_{\mathrm{gq}}^{*}=\mathrm{K}_{\mathrm{gp}}\left(\mathrm{i}_{\mathrm{gq}}^{*}-\mathrm{i}_{\mathrm{gq}}\right)+\mathrm{k}_{\mathrm{gi}} \int\left(\mathrm{i}_{\mathrm{gq}}^{*}-\mathrm{i}_{\mathrm{gq}}\right) \mathrm{dt}+\omega_{\mathrm{o}} \mathrm{L}_{\mathrm{g}} \mathrm{i}_{\mathrm{gd}}+\mathrm{k}_{2} \mathrm{~V}_{\mathrm{sq}} \\
& \mathrm{i}_{\mathrm{gq}}^{*}=\mathrm{K}_{\mathrm{q}} \operatorname{sqrt}\left(\mathrm{V}_{\mathrm{dc}}^{2 *}-\mathrm{V}_{\mathrm{dc}}^{2}\right)+\mathrm{k}_{\mathrm{qi}} \int\left(\mathrm{V}_{\mathrm{dc}}^{*}-\mathrm{V}_{\mathrm{dc}}\right) \mathrm{dt}+\mathrm{R}_{\mathrm{dc}} \mathrm{V}_{\mathrm{dc}} \\
& \mathrm{i}_{\mathrm{gd}}^{*}=\mathrm{K}_{\mathrm{d}} \operatorname{sqrt}\left(\mathrm{V}_{\mathrm{s}}^{2 *}-\mathrm{V}_{\mathrm{s}}^{2}\right)+\mathrm{k}_{\mathrm{di}} \int\left(\mathrm{V}_{\mathrm{s}}^{*}-\mathrm{V}_{\mathrm{s}}\right) \mathrm{dt}
\end{aligned}
$$

The rotating direct and quadrature reference voltages of rotor are converted into stationary abc frame parameters by using inverse parks transformation. Slip frequency is used to generate sinusoidal and cosine parameters for inverse parks transformation.

\subsection{Rotor speed sensing by using sensor-less control technique}

The sensor-less speed control for DFIG system with stator and rotor flux observers are shown in Figure 9a. The three phase stator voltage and currents are converted into two phase dq voltages and current by using Park's transformation. The dq axis stator voltage and current are transformed into dq axis stator flux based on equations $6 \mathrm{~b}$ and $7 \mathrm{~b}$. The internal structure for $\mathrm{dq}$ axis flux derivations are shown in Figure $9 \mathrm{~b}$ and 9c. The derived rotor and stator flux are compared and is controlled to estimate rotor speed by using PI controller. The blocks G1 and $\mathrm{G} 2$ are $\mathrm{Pl}$ controller functional blocks. The speed is estimated and is termed as $\mathrm{Wr}$ and is integrated to get rotor angle. The angle is multiplied with trigonometric SIN and COS terms and is given to mux to get sin_cos parameters and the total setup can be used as phase locked loop (PLL). This sin_cos helps in estimating exact phase sequence and for locking the new system to reference grid.

The estimated speed Wr is given as input for RSC controller as shown in Figure 6b. From the lookup table, reference rotor speed is estimated from optimal power block, which is obtained from MPPT algorithm explained earlier.

\subsection{Behaviour of mechanical and electrical system with the variation in wind sped and reactive power}

The mechanical to electrical relationship is explained as follows. The rotor speed can be expressed as

$$
\omega_{\mathrm{r}}=(1-\mathrm{s}) \omega_{\mathrm{s}}=\mathrm{p} \eta \omega_{\omega \mathrm{t}}
$$

Where $s$ is slip of DFIG, $p$ is pair of poles of DFIG; $\eta$ is gear box ratio and $\omega_{\omega t}$ is wind turbine speed. With the change in wind speed and depending on gears ratio and number of field poles, the rotor speed varies is shown in equation 33. When rotor speed varies, reference quadrature axis current changes, thereby current flow in the rotor circuit varies. The stator output also varies with variation in wind turbine speed and DFIG output power. When slip varies, the voltage in rotor circuit also varies which can be explained as per equations 8 and 9 . Further change in rotor voltage leads to change in rotor current, there by rotor power flow also varies. 


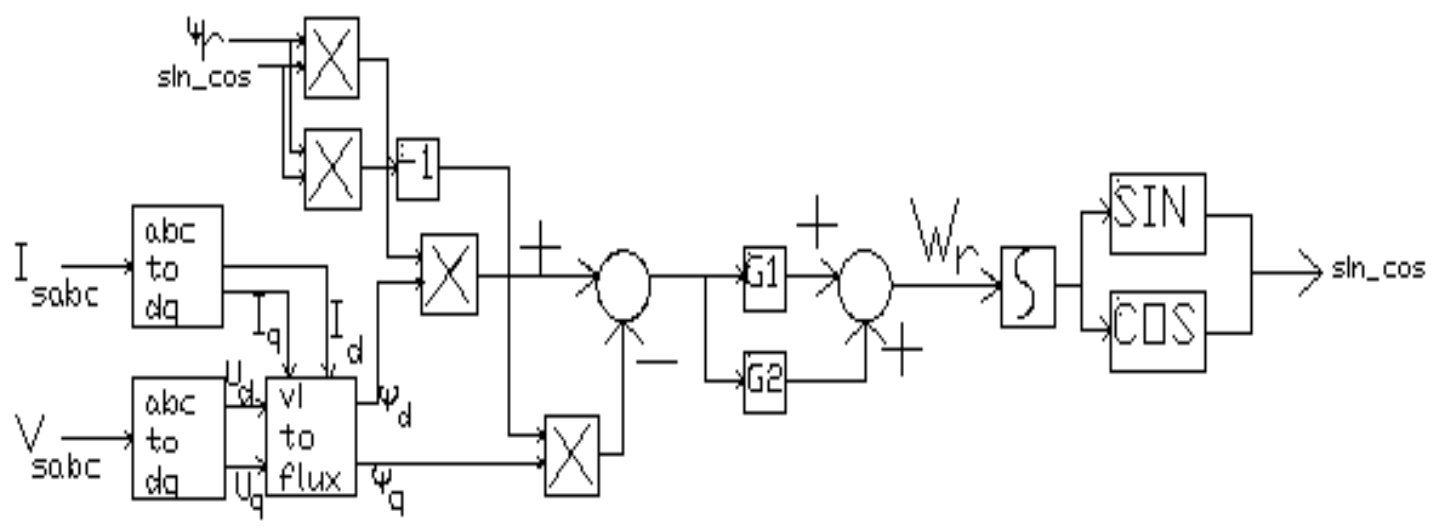

(a)

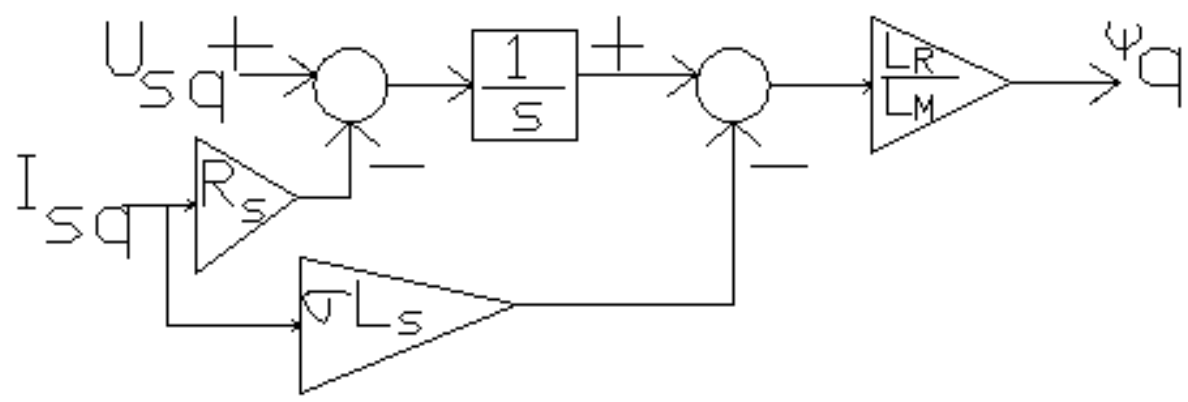

(b)

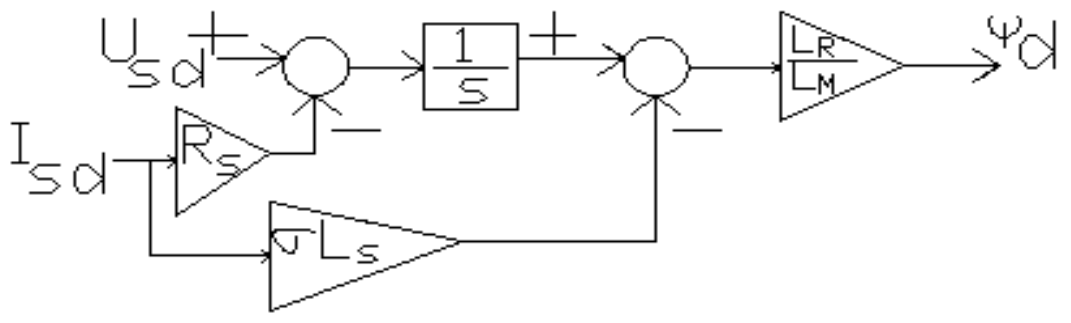

(c)

Figure 9. The sensor-less speed control for DFIG system, a). Estimation of rotor speed with stator voltage and current and rotor flux as inputs, b) Derivation of stator q-axis flux from q- axis stator voltage and current equation $7 b, c)$. Derivation of stator $d$-axis flux from $d$ - axis stator voltage and current from equation $6 \mathrm{~b}$

The mechanical turbine tip speed ratio (TSR) can be written in terms of radius of turbine wings $(R)$, angular stator speed ( $\omega s)$, pole pairs and gear box ratio as

$$
\lambda=\frac{R \omega_{s}}{p \eta v_{w}}(1-s)
$$

Increase in stator or grid frequency, TSR increases and vice versa. Similarly with increase in rotor speed or wind speed, TSR decreases and vice versa. Hence when an electrical system gets disturbed, mechanical system also will get some turbulence and electrical to mechanical system is tightly interlinked. The steady state behavior of overall system must satisfy the relation below. 


$$
\Delta \mathrm{P}=\frac{-\mathrm{P}_{\omega \mathrm{t}}}{(1-\mathrm{s})}-\mathrm{P}_{\mathrm{em}}=0
$$

Under normal conditions, the change in turbine output has to be compensated by electrical power output from DFIG. Otherwise slip gets changed and thereby rotor speed changes. Hence imbalance in mechanical to electrical power output ratios, the slip changes. With the change in coefficient of power $\mathrm{Cp}$, the mechanical power varies. The mechanical power changes mostly when wind speed or air density around the turbine wings changes. The electrical power from DFIG changes when mechanical power changes or rotor speed changes or load demand from grid varies.

\section{Results and Discussion}

The dynamic performance of the DFIG system is shown in Figure 9 is investigated under three different cases and the rating specifications for DFIG and wind turbine parameters are given in appendix. The wind speed change in all cases in meters per seconds as 8, 15, 20 and 10 at 15, 25 and 35 seconds. The reactive power and voltage value change in individual two cases with change in time is from $-0.6 \mathrm{pu}$ at 12 seconds to $0 \mathrm{pu}$ change at 20 seconds. It was further changed from $0 \mathrm{pu}$ to $+0.6 \mathrm{pu}$ magnitude at 30 seconds. In general wind speed will change with time which is a natural phenomenon, demand in lagging or leading reactive power requirement will come into picture because of change in load. Due to addition of large furnace or induction motor or non linear type load, leading reactive power greater than 0pu is required, while for light load lagging reactive power is required (<0pu). Hence DFIG will become better generator source if immediately it can supply any desired reactive power effectively. The change in grid terminal voltage takes place when suddenly switching on or off large loads or due to small faults near point of common coupling (PCC). The effect of change in wind speed, change in wind speed with reactive power and change in wind speed with grid terminal voltages on generator and turbine parameters are studied.

\section{Case Studies}

\subsection{Case A: Change in TSR and Cp with wind speed, reactive power and grid voltage}

The changes in tip- speed ration and power coefficient $\mathrm{Cp}$ with change in wind speed alone is shown in Figure 10 (a), with both reactive power and wind speed variation in Figure 11 (b) and variation with grid terminal voltage and wind speed both is shown in Figure 10 (c).
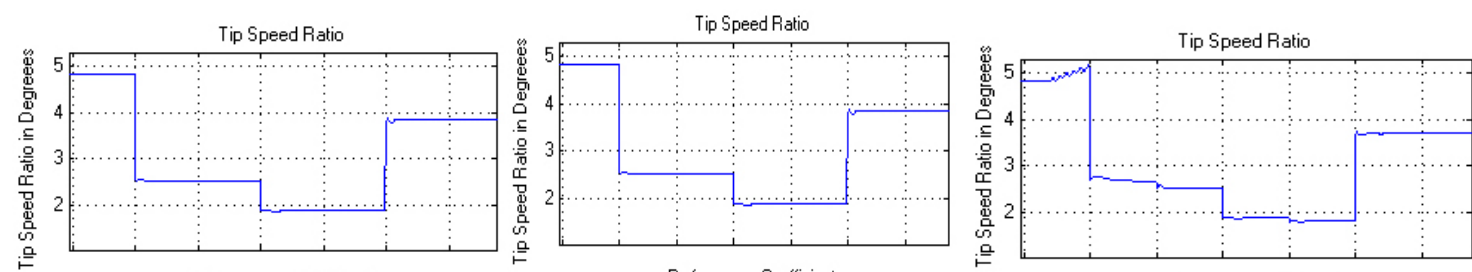

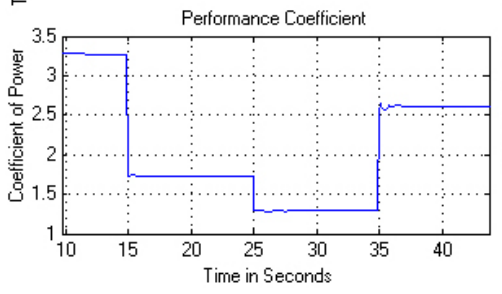

(a)

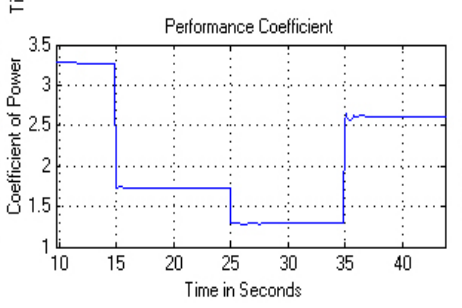

(b)

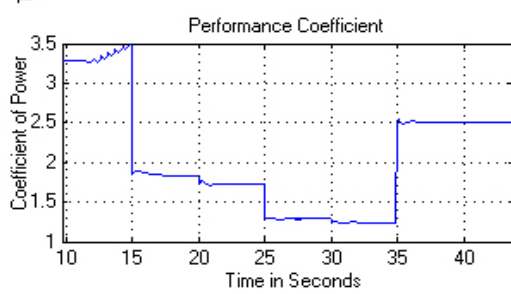

(c)

Figure 10. Tip speed ratio and Coefficient of power $\mathrm{Cp}$ for (a) change in wind speed alone, (b) reactive power change \& wind speed variation, (c) both grid voltage \& wind speed changes 
It can be observed that when wind speed is at $8 \mathrm{~m} / \mathrm{s}$, tip speed ratio (TSR) is high near 4.8 degrees and slowly decreases to 2.6 degrees at $15 \mathrm{~s}$ when speed increases to $15 \mathrm{~m} / \mathrm{s}$, further increased to 1.90 at $25 \mathrm{~s}$ when speed of wind is $20 \mathrm{~m} / \mathrm{s}$ and decreased to 3.90 when wind speed decreased to $10 \mathrm{~m} / \mathrm{s}$ at $35 \mathrm{~s}$. In the similar way, $\mathrm{Cp}$ is also changing from 3.25 to 1.7 at $15 \mathrm{~s}$, and further decreased to 1.25 at $25 \mathrm{~s}$, and then increased to 2.55 at 35 seconds with wind speed variation from 8 to 15 and then to 20 , and $10 \mathrm{~m} / \mathrm{s}$.

The variation in TSR and $\mathrm{Cp}$ with change in reactive power is independent and has no effect as shown in Figure 10 ( $a$ and $b$ ). However, with change in grid terminal voltage, a very small change in TSR and $\mathrm{Cp}$ can be observed. It is due to the fact that the TSR and Cp depends on parameters as described by equations 1 to 5 and is independent on voltage and reactive power. The TSR and $C p$ are blade size and shape with change in ambient temperature and wind speed dependant natural parameters.

\subsection{Case B: Change in electromagnetic torque and rotor speed with wind speed, reactive power and grid voltage}

The reference mechanical turbine torque and generator torque with magnitudes overlapping and variation of rotor speed for all three cases comparison is shown in Figure 11. In this the reference and actual torque waveform with blue color is turbine reference torque and pink color lines are for generator torque. It can be observed in Figure 11 ( $a, b$ and $c)$, with increase in wind speed, torque is increasing and vice-versa. Till time up to 15 seconds, wind speed is at low value of $8 \mathrm{~m} / \mathrm{s}$, so torque is at $-0.2 \mathrm{pu}$ and increased to $-0.5 \mathrm{pu}$ at $15 \mathrm{~s}$ with increase in wind speed to $15 \mathrm{~m} / \mathrm{s}$. The torque further increased to $-0.9 \mathrm{pu}$ when wind speed is $20 \mathrm{~m} / \mathrm{s}$ and decreased to $-0.28 \mathrm{pu}$ when speed decreased to $10 \mathrm{~m} / \mathrm{s}$. there are small surges in torque waveform because of sudden change in wind speed. These surges can be minimized if a flywheel is used between turbine and generator, but has disadvantage of increase in weight, cost and maintenance. With the change in wind speed, rotor speed is also varying but is maintained nearly at constant value of 1.3pu RPM. In the first case, reactive power was at 0pu and grid terminal voltage is $1 \mathrm{pu}$.
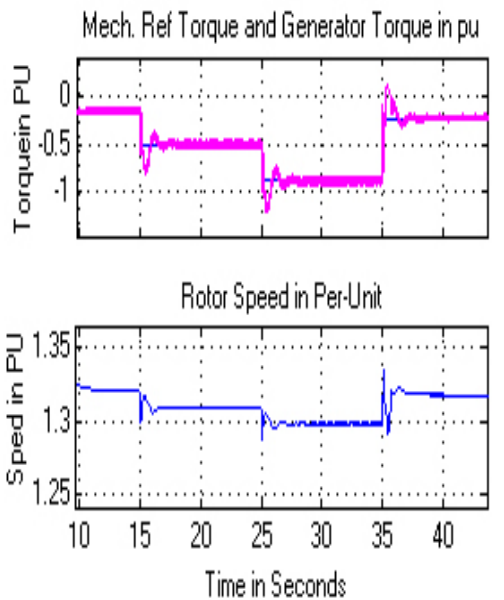

(a)

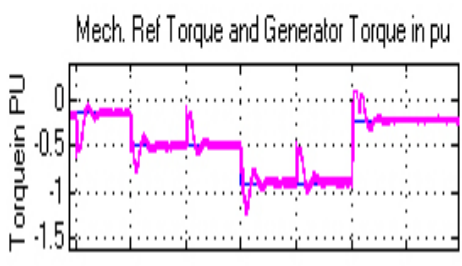

Rotor Speed in Per.Unit

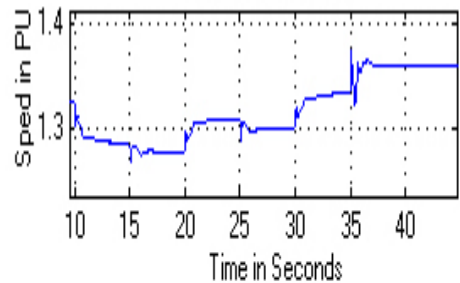

(b)

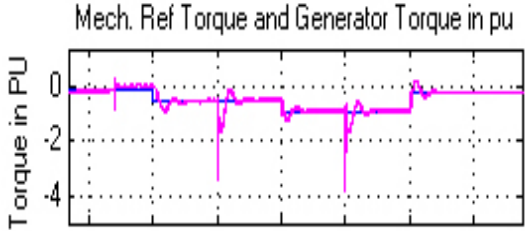

Rotor Speed in Per.Unit

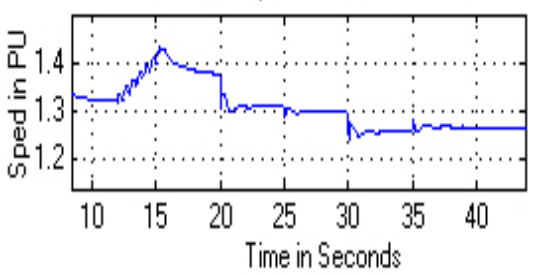

(c)

Figure 11. Reference and actual generator torque and rotor speed variation with time for: (a) change in wind speed alone, (b reactive power change \& wind speed variation, (c) both grid voltage \& wind speed changes

The changes in torque has effect with change in reactive power as in Figure 11 (b) and further more surges been observed when grid voltage disturbance occurred as in Figure 11 (c) is taking place. When reactive power is lagging at $-0.6 \mathrm{pu}$, there is a small surge in torque at 20 seconds. Generator speed is also low at $1.27 \mathrm{pu}$ at $-0.6 \mathrm{pu}$ reactive power, while at $0 \mathrm{pu}$ reactive 
power, it is 1.32pu speed. But rotor speed increased to $1.4 \mathrm{pu}$ speed at low terminal grid voltage of $0.8 \mathrm{pu}$. When, reactive power changes to $0 \mathrm{pu}$ from $-0.6 \mathrm{pu}$, rotor speed increased to $1.3 \mathrm{pu}$ from $1.27 \mathrm{pu}$ and grid terminal voltage changes to $1 \mathrm{pu}$ from $0.8 \mathrm{pu}$ between 20 to 30 seconds. Speed further increased to $1.35 \mathrm{pu}$ with leading reactive power of $+0.6 \mathrm{pu}$ and decreased when grid voltage increased from $1 \mathrm{pu}$ to $1.2 \mathrm{pu}$. Therefore rotor speed increases if reactive power changes from lagging (-ve) to leading (+ve) and rotor speed decreases with increase in grid terminal voltage beyond 1 pu value in rms. The surges in torque will be observed very high when terminal grid voltage changes is due to the fact of change in mechanical power is not that faster than in comparison with electrical power change, which can be understandable using equal area criterion for SMIB system.

\subsection{Case C: Change in stator voltage and current with wind speed, reactive power and grid voltage}

The change in stator voltage and current with all three cases is shown in Figure 12 and zoomed voltage and current is shown in Figure 13. It can be observed that the stator terminal voltage is constant with change in wind speed as in Figure 12 (a) or with change in reactive power as in Figure 12 (b). There is an increase in current from $0.18 \mathrm{pu}$ to $0.5 \mathrm{pu}$ at 15 seconds with increase in wind speed from 8 to $15 \mathrm{~m} / \mathrm{s}$ and further increased to $0.9 \mathrm{pu}$ amps when speed increased to $20 \mathrm{~m} / \mathrm{s}$ and decreased to $0.3 \mathrm{pu}$ amps when speed of wind is $10 \mathrm{~m} / \mathrm{s}$ as shown in Figure 12 (c). But with change in reactive power, terminal voltage is nearly constant but there is a large change in current and voltage angle, hence large magnitude and angle change in current. When reactive power $(Q)$ change from $0 \mathrm{pu}$ to $-0.6 \mathrm{pu}$, current increased from $0.15 \mathrm{pu}$ $0.5 \mathrm{pu}$ amps and decreased to $0.5 \mathrm{pu}$ amps when $\mathrm{Q}$ changes from $-0.6 \mathrm{pu}$ to $0 \mathrm{pu}$ and increased to $1 \mathrm{pu}$ amps when speed of wind is $20 \mathrm{~m} / \mathrm{s}$ and reactive power is $0.6 \mathrm{pu}$.

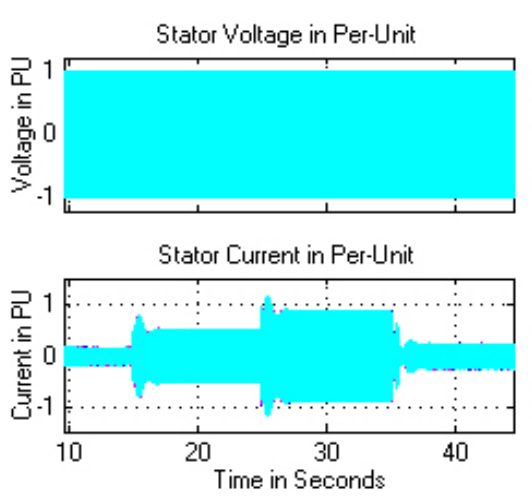

(a)

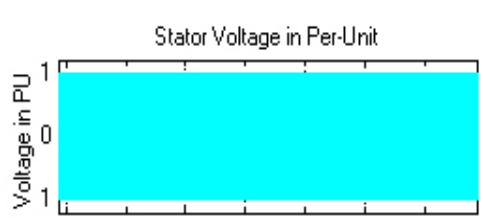

Stator Current in Per-Unit

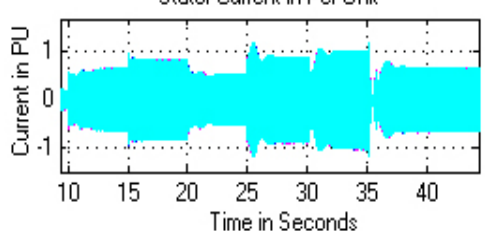

(b)

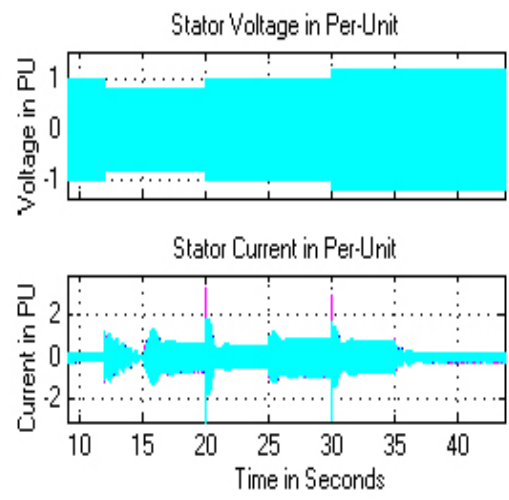

(c)

Figure 12. Stator voltage and current for (a) change in wind speed alone, (b) reactive power change \& wind speed variation, (c) both grid voltage \& wind speed changes

With sudden decrease in grid terminal voltage from $1 \mathrm{pu}$ to $0.8 \mathrm{pu}$ volts at 12 seconds, slowly stator current decreased exponentially when wind speed is very low of $0.1 \mathrm{pu}$ amps at $8 \mathrm{~m} / \mathrm{s}$ and this current was improved to $1 \mathrm{pu}$ when wind speed increased to $15 \mathrm{~m} / \mathrm{s}$. But when terminal voltage changed to $1 \mathrm{pu}$ from $0.8 \mathrm{pu}$ at $20 \mathrm{~s}$, current again reached to normal value of $0.5 \mathrm{pu}$ amps as in case 1 and the current increased to again $1 \mathrm{pu}$ when wind speed reaches $20 \mathrm{~m} / \mathrm{s}$. when the grid terminal voltage increased to $1.2 \mathrm{pu}$ from $1 \mathrm{pu}$, the stator current again decreased to $0.8 \mathrm{pu}$ amps and when wind speed finally reaches $10 \mathrm{~m} / \mathrm{s}$ with voltage at $1.2 \mathrm{pu}$, the current is $0.2 \mathrm{pu}$ Amps as in Figure 12 (c) and 12 (a). Hence with increase in voltage at constant wind speed, current decreases and with increase in wind speed at same voltage current will increase and vice-versa. The zoomed stator voltage and current waveform for a particular time period of nearly 1 second for all three cases is shown in Figure 13. In the similar way as does in stator voltage and current, rotor voltage and current will also vary, but rotor current is bidirectional unlike stator current does. 


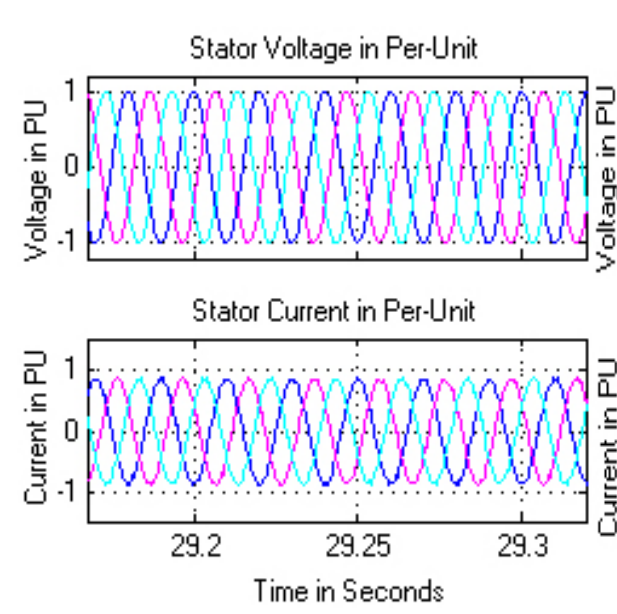

(a)
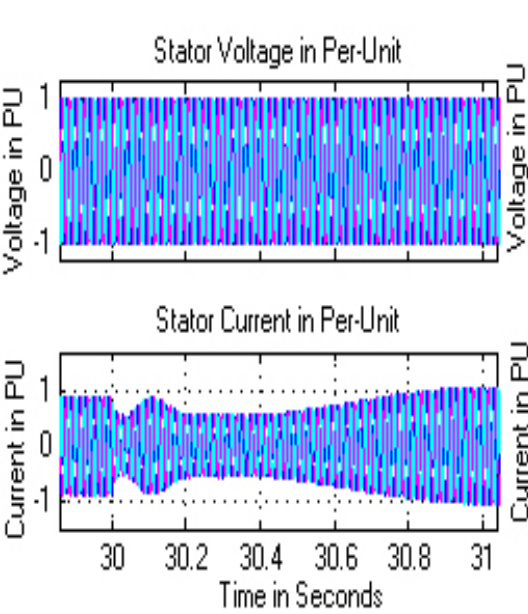

(b)
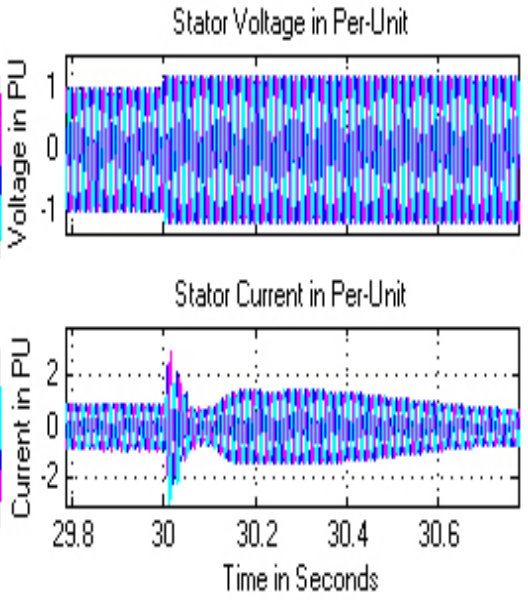

(c)

Figure 13. Stator voltage and current for (a) change in wind speed alone, (b) reactive power change \& wind speed variation, (c) both grid voltage \& wind speed changes

\subsection{Case D: Change in rotor voltage and current with wind speed, reactive power and grid voltage}

In all the three cases, rotor voltage is nearly constant at $0.32 \mathrm{pu}$, but current is varying with variation in wind speed alone Figure 14 (a), with both wind speed and reactive power change in Figure 14 (b) and for voltage and wind speed variation as in Figure 14 (c). For the first case, with increase in rotor speed, rotor current increases and vice versa. When wind speed is at $8 \mathrm{~m} / \mathrm{s}$, rotor current is $0.2 \mathrm{pu}$, when wind speed reaches $15 \mathrm{~m} / \mathrm{s}$, rotor current is $0.5 \mathrm{pu}$, it is $0.9 \mathrm{pu}$ when wind speed is $20 \mathrm{~m} / \mathrm{s}$ and is $0.3 \mathrm{pu}$ when wind speed is $10 \mathrm{~m} / \mathrm{s}$ as shown in Figure 14 (a) and zoomed picture in Figure 15(a). But when reactive power at $-0.6 \mathrm{pu}$, rotor current is $0.8 \mathrm{pu}$ is even low at $8 \mathrm{~m} / \mathrm{s}$ wind speed and increased to $1 \mathrm{pu}$ amps when wind speed reaches $15 \mathrm{~m} / \mathrm{s}$ as in Figure 14 (b). When reactive power reaches $1 \mathrm{pu}$, rotor current is $0.5 \mathrm{pu}$ amps at wind speed of $15 \mathrm{~m} / \mathrm{s}$ and for leading reactive power of $+0.6 \mathrm{pu}$, the rotor current is again $1 \mathrm{pu}$ at wind speed of $20 \mathrm{~m} / \mathrm{s}$ and $0.5 \mathrm{pu}$ amps at $10 \mathrm{~m} / \mathrm{s}$ wind speed. With increase in wind speed or at leading or lagging reactive power, rotor current is also increasing like stator current.

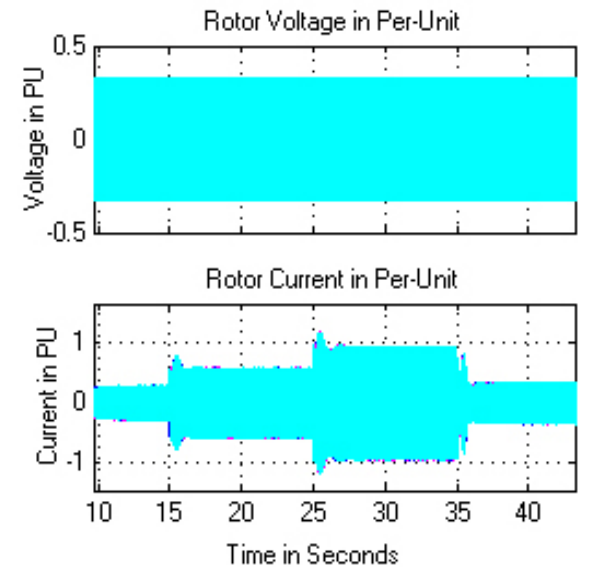

(a)

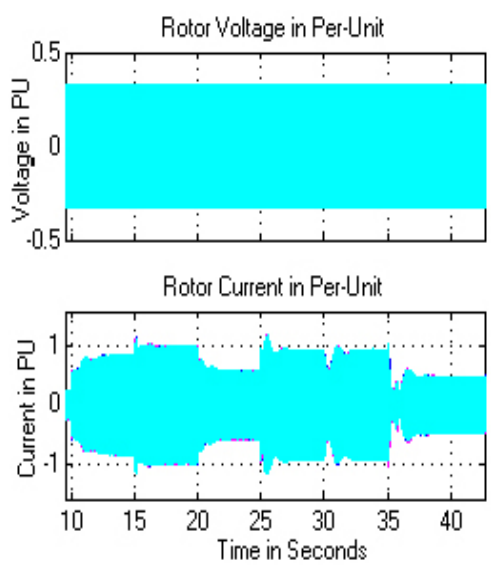

(b)

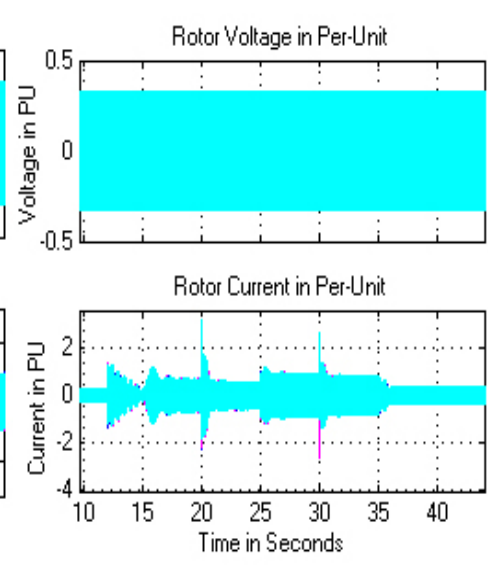

(c)

Figure 14. Rotor voltage and current (a) change in wind speed alone, (b) reactive power change $\&$ wind speed variation, (c) both grid voltage \& wind speed changes 
In the same scenario, rotor current is decreasing with increase in grid terminal voltage and vice-versa but without any appreciable change in rotor voltage. With sudden changes in voltage at 12, 20 and 30 seconds as in Figure 14 (c), there are few spikes in rotor current due to sudden reversal of current magnitude and angle with respect to terminal voltages respectively. The zoom in rotor voltage and current in the time period between 29.8 to 30.6 seconds for change in voltage and wind speed is shown in Figure 15 (c).

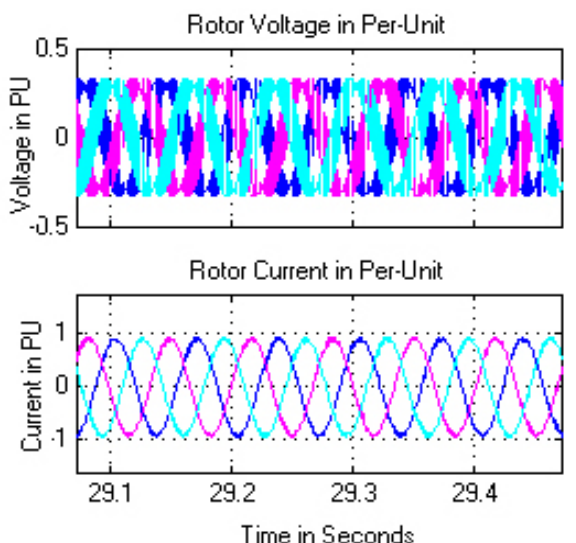

(a)

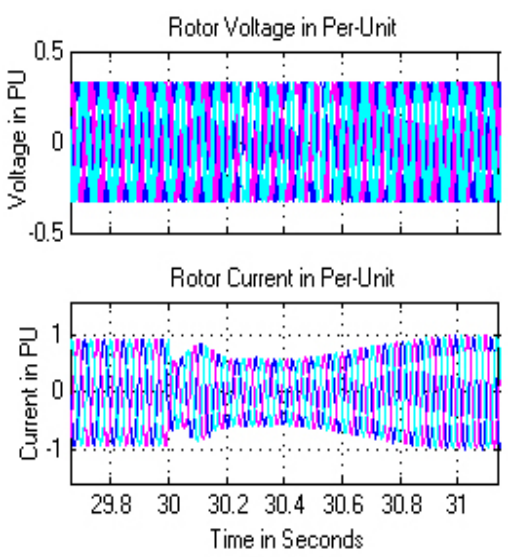

(b)

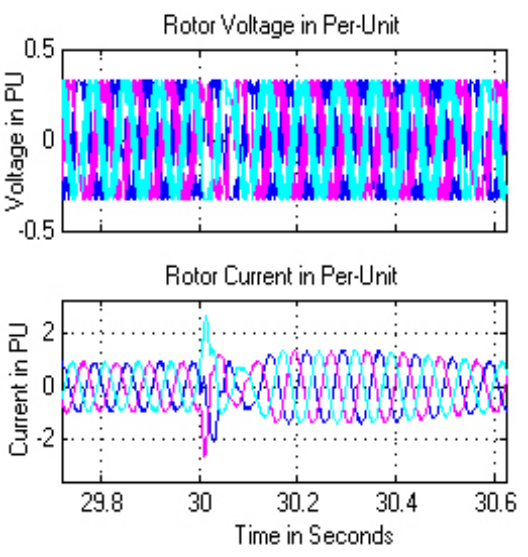

(c)

Figure 15. Rotor voltage and current for (a) change in wind speed alone, (b) reactive power change \& wind speed variation, (c) both grid voltage \& wind speed changes

\subsection{Case E: Change in stator real and reactive power with wind speed, reactive power and grid voltage}

The stator real and reactive power flow for all three cases is shown in Figure 16. The reference power which is the mechanical power output from turbine and actual generator real power change is shown in Figure 17. In the first case with change in wind speed, with very low wind speed of $8 \mathrm{~m} / \mathrm{s}$, output stator real power is $0.1 \mathrm{pu}$ watts till 15 seconds. When wind speed reaches $15 \mathrm{~m} / \mathrm{s}$, stator real power increased to $0.5 \mathrm{pu}$ and further increased to $0.8 \mathrm{pu}$ for $20 \mathrm{~m} / \mathrm{s}$ wind speed at $25 \mathrm{~s}$ and decreased to $0.2 \mathrm{pu}$ power at $35 \mathrm{~s}$ for $10 \mathrm{~m} / \mathrm{s}$ speed as shown in Figure 16 (a). During the change in wind speed, real power alone is changing and reactive power is constant at reference of Opu. There are few surges in the reactive power due to change in voltage angle with respect to grid and also mainly due to change in stator and rotor current flows and rotor voltage change. With the change in reactive power demand from grid from 0 pu to $-0.6 \mathrm{pu}$ and $+0.6 \mathrm{pu}$ at 12 and 30 seconds are shown in Figure 16 (b). It can be observed that with change in reactive power from $0 \mathrm{pu}$ to $-0.6 \mathrm{pu}$, reactive power from generator is changing with a small time lag of $0.8 \mathrm{~s}$ and real power maintained nearly constant value of $0.1 \mathrm{pu}$ at $8 \mathrm{~m} / \mathrm{s}$ wind speed. Similarly with reactive power changing to $0 \mathrm{pu}$ and $+0.6 \mathrm{pu}$, the reactive power is changing within 1 second and real power is almost constant with small surges in real stator power during this transient. 


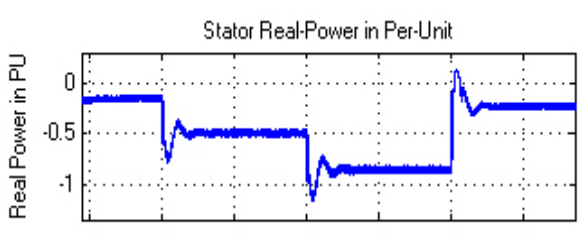

Stator Reactive-Power in Per-Unit

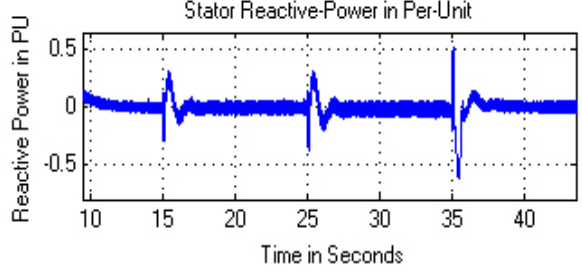

(a)

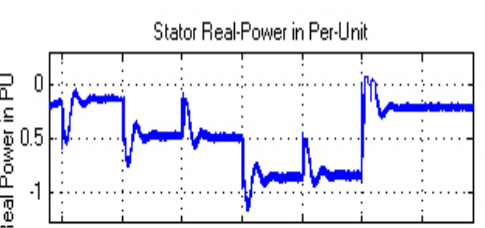

Stator Reactive.Power in Per-Unit

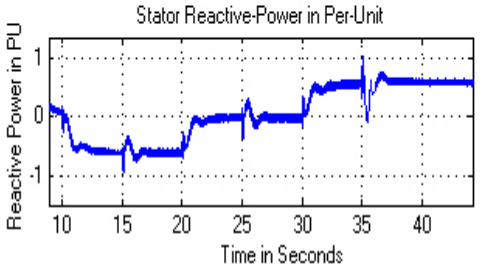

(b)

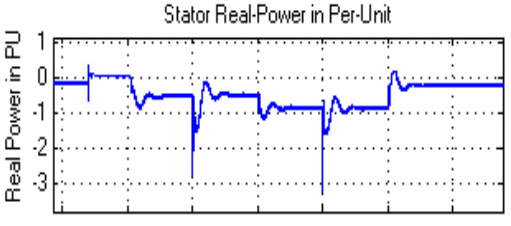

Stator Reactive-Power in Per-Unit

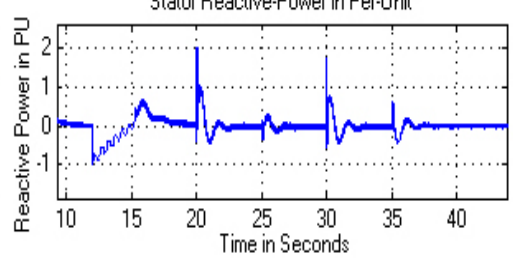

(c)

Figure 16. Stator real and reactive power waveform with time for (a) change in wind speed alone, (b) reactive power change \& wind speed variation, (c) both grid voltage \& wind speed changes

In third case with both voltage and wind speed changing, with the grid voltage variation from 1 to $0.8 \mathrm{pu}$ at 12 th second, real power which is at $0.1 \mathrm{pu}$ changed to $0.05 \mathrm{pu}$ and reactive power which is at $0 \mathrm{pu}$ reached $1 \mathrm{pu}$ at this 12 th second instant and slowly decaying to reach to reference 0 pu value. This change in reactive power is to make voltage of stator to get adjusted to grid voltage without losing synchronism.

\subsection{Case F: Comparison of reference and actual stator real and reactive power with change in wind speed, reactive power and grid voltage \\ The reference mechanical power output is shown with pink line and generator power is} with blue line for the first case is shown in Figure 17 (a). It can be observed that, nearly generator actual power is matching with reference power and the mismatch is because of looses in turbine, gear wheels and generator and this mismatch is inevitable. With increase in wind speed, reference power is increasing and vice versa. When wind speed is $8 \mathrm{~m} . \mathrm{s}$, output electrical real power is $0.1 \mathrm{pu}$ till $15 \mathrm{~s}$ and reaches 0.4 and $0.8 \mathrm{pu}$ at 15 and 25 seconds with wind speed changing from 15 to $25 \mathrm{~m} / \mathrm{s}$ and then decreases to $0.2 \mathrm{pu}$ due to decrease in wind speed to $10 \mathrm{~m} / \mathrm{s}$ respectively. With the change in voltage at grid, stator terminal real power is maintained at constant value but with surges at instant of transient but reactive power is adjusting till stator voltage reaches the grid voltage for maintaining synchronism as shown in Figure 16 (c) and 17 (c). At the instant of 20 and 30 seconds, there is surge in real and reactive powers but were maintaining constant stator output real powers of 0.5 and $0.8 \mathrm{pu}$ watts and $0 \mathrm{pu}$ Var as in Figure 16 (c).

The Figure $6 \mathrm{~h}$ is the output real and reactive powers from stator and rotor adding vector ally as shown in blue color lines and reference real power from turbine and reactive power from grid terminal in pink. To meet the desired grid reactive power, both stator and rotor has to supply for faster dynamics with an aid to RSC and GSC control schemes and is achieving as shown in Figure 17 (b). With the change in wind speed and reactive power, real power from generator is matching its reference value for case 2, but small deviation can be observed from time 30 to 35 seconds is due to sudden change in reactive power demand from grid and the deviation in real power is from $0.8 \mathrm{pu}$ to $0.7 \mathrm{pu}$ which is small. However reactive power is following its trajectory within 1 second.

In the case 3, both voltage and reactive power changing with time, total output real and reactive powers from stator and rotor is delivering to grid to meet the desired grid power demand. Unlike with change in reactive power, change in voltage is not affecting any deviation in real power and is following the trajectory nearly accurate with maximum deviation of $5 \%$ in real power. The reactive power change with grid voltage is high when voltage decreased from 1 pu to 0.8 pu volts.

IJEEI Vol. 3, No. 4, December 2015 : $239-260$ 


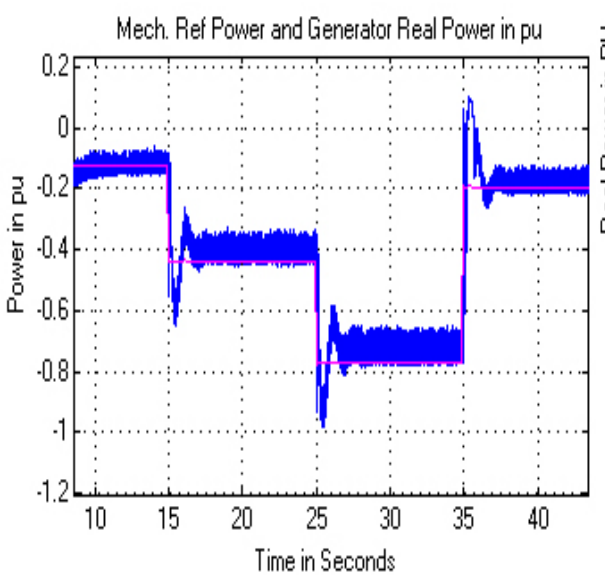

(a)

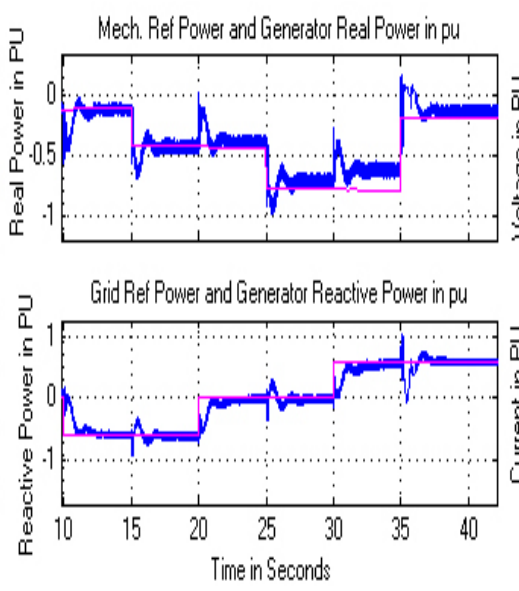

(b)

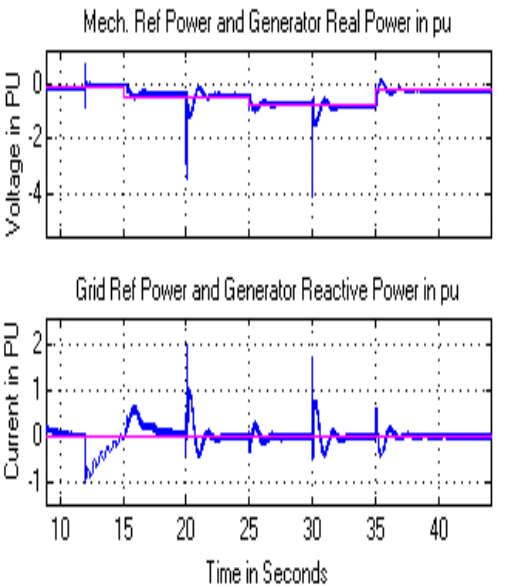

(b)

Figure 17. generator reference and actual real power waveform with time for (a) change in wind speed alone, generator real and reactive power flows for actual and reference for change in (b) reactive power change \& wind speed variation, (c) both grid voltage \& wind speed changes

When wind speed is increasing, mechanical and electrical torques are increasing without any change in stator reactive power. Variation in grid reactive power causes quadrature currents on both stator and rotor to change but torque, speed or real powers from stator or rotor remains unaltered. The variation in grid terminal voltage, a very small change in TSR and Cp can be observed. It is due to the fact that the TSR and Cp depends on parameters and is independent on voltage and reactive power. The TSR and $\mathrm{Cp}$ are blade size and shape with change in ambient temperature and wind speed dependant natural parameters. With increase in voltage at constant wind speed, current decreases but, with increase in wind speed at same voltage, current will increase and the decrease in wind speed caused current from stator to rotor decreases with stator voltage as constant as depicted by grid. In the similar way as does in stator voltage and current, rotor voltage and current will also vary, but rotor current is bidirectional unlike stator current does. The change in voltage at grid, stator terminal real power is maintained at constant value but with surges at instant of transient but reactive power is adjusting till stator voltage reaches the grid voltage for maintaining synchronism. To meet the desired grid reactive power, both stator and rotor has to supply for faster dynamics and it depends on faster action of RSC and GSC control schemes. The change in three cases is tabulated below. The variation in reactive power and grid voltage variations during the respective time period is shown in Table 2 and Table 3 . In the Table 1, due to change in wind speed input to turbine alone, generator and wind turbine parameters change are summarized. There are surges produced in electromagnetic torque (EMT) due to variations in reactive power and grid voltage. Large spikes in stator current and rotor current are produced due to sudden increase or decrease in grid voltage. Certain deviations in rotor speed can be observed due to change in reactive power or grid voltage. It is due to variation in current flow in the rotor circuit, thereby variation in rotor flux and hence rotor speed.

Table 1. Change in Reactive power during the time period along with change in wind speed

\begin{tabular}{cccc}
\hline Time range $(\mathrm{s})$ & $0 .-20$ & $20-30$ & $30-50$ \\
\hline Reactive power $(\mathrm{pu})$ & -0.6 & 0 & 0.6 \\
\hline
\end{tabular}

Table 2. Change in grid voltage during the time period along with change in wind speed

\begin{tabular}{lcccc}
\hline Time range $(\mathrm{s})$ & $0 .-12$ & $12-20$ & $20-30$ & $30-50$ \\
\hline Reactive power $(\mathrm{pu})$ & 1 & 0.8 & 1 & 1.2 \\
\hline
\end{tabular}


Table 3. Variation of turbine and generator parameters with change in wind speed input

\begin{tabular}{lcccc} 
Wind speed (m.s) & 8 & 15 & 20 & 10 \\
Time (s) & 10 & 15 & 25 & 35 \\
TSR (degree) & 4.9 & 2.5 & 1.95 & 3.95 \\
Cp & 3.25 & 1.75 & 1.25 & 2.60 \\
EMT (pu) & -0.2 & -0.5 & -0.8 & -0.3 \\
Rotor speed (pu) & 1.32 & 1.31 & 1.30 & 1.33 \\
Stator current (pu) & 0.2 & 0.5 & 0.8 & 0.3 \\
Rotor current (pu) & 0.25 & 0.55 & 0.90 & 0.35 \\
Stator power (pu) & -0.2 & -0.5 & -0.8 & -0.3 \\
Rotor power (pu) & 0 & 0 & 0 & 0 \\
\hline
\end{tabular}

\section{Conclusion}

From the proposed control scheme, the torque, speed and reactive power control of DFIG is very specific. With change in wind speed, electromagnetic torque surges are low and the variation in wind speed is not getting the generator rotor speed variation is due to better transition in gear wheel mechanism. Reactive power demand from grid is accurate which can be met by proper control action of RSC and GSC. The proposed methodology is accurate and following all basic mathematical equations explained in previous section. Distinct from reactive power variation, change in voltage is not affecting any deviation in real power and is following the trajectory nearly accurate with maximum deviation of $5 \%$ in real power. The reactive power change with grid voltage is high when voltage decreased from $1 \mathrm{pu}$ to $0.8 \mathrm{pu}$ volts. Hence the proposed control scheme can be applied with ever changing transients like large variation in wind speed, reactive power and grid voltage. The system is very stable without losing synchronism when grid voltage is increasing or decreasing to a $\pm 0.2 \mathrm{pu}$ change from nominal voltage value.

\section{Appendix}

The parameters of DFIG used in simulation are,

Rated Power $=1.5 \mathrm{MW}$, Rated Voltage $=690 \mathrm{~V}$, Stator Resistance Rs $=0.0049 \mathrm{pu}$, rotor Resistance $\mathrm{Rrl}=0.0049 \mathrm{pu}$, Stator Leakage Inductance Lls $=0.093 \mathrm{pu}$, Rotor Leakage inductance LIr1 $=0.1 \mathrm{pu}$, Inertia constant $=4.54 \mathrm{pu}$, Number of poles $=4$, Mutual Inductance Lm $=3.39 \mathrm{pu}, \mathrm{DC}$ link Voltage $=415 \mathrm{~V}$, Dc link capacitance $=0.2 \mathrm{~F}$, Wind speed $=14 \mathrm{~m} / \mathrm{sec}$.

Grid Voltage $=25 \mathrm{KV}$, Grid frequency $=60 \mathrm{~Hz}$.

Grid side Filter: $\mathrm{Rfg}=0.3 \Omega$, $\mathrm{Lfg}=0.6 \mathrm{nH}$

Rotor side filter: $\mathrm{Rfr}=0.3 \mathrm{~m} \Omega$, $\mathrm{Lfr}=0.6 \mathrm{nH}$

Wind speed variations: 8, 15, 20 and 10 at 15,25 and 35 seconds.

Reactive power change: -0.6 to 0 and $+0.6 \mathrm{pu}$ at 20 and 30 seconds.

Grid voltage change: 0.8 to 1 and to $1.2 \mathrm{pu}$ at 20 and 30 seconds.

\section{Nomenclature}

$L_{l s}, L_{l r}, L_{m} \quad$ Stator or Rotor leakage reactance and magnetizing reactance

$R_{S}, R_{r} \quad$ Stator or Rotor resistance

$V_{s d}, V_{r d}, V_{s q}, V_{r q}$ two axis stator or rotor voltage

$\mathrm{I}_{s d}, I_{r d}, I_{s q}, \mathrm{I}_{r q}$ two axis stator or rotor current

$\Psi_{s d}, \Psi_{r d}, \Psi_{s q}, \Psi_{r q}$ two axis stator or rotor flux linkage

$P_{s}, P_{r} \quad$ Stator or Rotor real power

$Q_{s}, Q_{r} \quad$ Stator or Rotor reactive power

$\omega_{s}, \omega_{r} \quad$ Stator or Rotor speed

$T_{e} \quad$ Electromagnetic torque

$p \quad$ Pole pairs

s Slip

p.u. per unit 


\section{References}

[1] Aghanoori, N, Mohseni, M, Masoum, MAS. Fuzzy approach for reactive power control of DFIG-based wind turbines. IEEE PES Innovative Smart Grid Technologies Asia (ISGT). 2011: 1-6.

[2] Syed Muhammad Raza Kazmi, Hiroki Goto, Hai-Jiao Guo, Osamu Ichinokura. A Novel Algorithm for Fast and Efficient Speed-Sensor less Maximum Power Point Tracking in Wind Energy Conversion Systems. IEEE Transactions On Industrial Electronics. 2011; 58(1): 29-36.

[3] Iwanski, G, Koczara, W. DFIG-Based Power Generation System With UPS Function for VariableSpeed Applications. IEEE Transactions on Industrial Electronics. 2008; 55(8): 3047-3054.

[4] Aktarujjaman, M, Haque, ME, Muttaqi, KM, Negnevitsky, M, Ledwich, G. Control Dynamics of a doubly fed induction generator under sub- and super-synchronous modes of operation. IEEE Power and Energy Society General Meeting - Conversion and Delivery of Electrical Energy in the 21st Century. 2008: 1-9.

[5] Iwanski, G, Koczara, W. DFIG-Based Power Generation System With UPS Function for VariableSpeed Applications. IEEE Transactions on Industrial Electronics. 2008; 55(8): 3047-3054.

[6] Dawei Zhi, Lie Xu. Direct Power Control of DFIG With Constant Switching Frequency and Improved Transient Performance. IEEE Transactions On Energy Conversion. 2007; 22(1): 110-118.

[7] Lie $\mathrm{Xu}$, Cartwright, P. Direct active and reactive power control of DFIG for wind energy generation. IEEE Transactions on Energy Conversion. 2010; 25(4): 1028-1039.

[8] Mustafa Kayıkc, Jovica V. Milanovi. Reactive Power Control Strategies for DFIG-Based Plants. IEEE Transactions On Energy Conversion. 2007; 22(2): 389-396.

[9] Stephan Engelhardt, Istvan Erlich, Christian Feltes, Jorg Kretschmann, Fekadu Shewarega. Reactive Power Capability of Wind Turbines Based on Doubly Fed Induction Generators. IEEE Transactions On Energy Conversion. 2011; 26(1): 364- 372.

[10] Gerardo Tapia, Arantxa Tapia, and J. Xabier Ostolaza. Proportional-Integral Regulator-Based Approach to Wind Farm Reactive Power Management for Secondary Voltage Control. IEEE Transactions On Energy Conversion. 2007; 22(2): 488- 498.

[11] Dongkyoung Chwa, Kyo-Beum Lee. Variable Structure Control of the Active and Reactive Powers for a DFIG in Wind Turbines. IEEE Transactions On Industry Applications. 2010; 46(6): 2545-2555.

[12] Lingling Fan, Haiping Yin, Zhixin Miao. On Active/Reactive Power Modulation of DFIG-Based Wind Generation for Interarea Oscillation Damping. IEEE Transactions On Energy Conversion. 2011; 26(2): 513-521.

[13] Hua Geng, Cong Liu, Geng Yang. LVRT Capability of DFIG-Based WECS Under Asymmetrical Grid Fault Condition. IEEE Transactions On Industrial Electronics. 2013; 60(6): 2495-2509.

[14] Shukla, RD, Tripathi, RK. Low voltage ride through (LVRT) ability of DFIG based wind energy conversion system II. Students Conference on Engineering and Systems (SCES). 2012: 1-6.

[15] Guzmán Díaz. Optimal primary reserve in DFIGs for frequency support. International journal of Electrical Power and Energy Systems. 2012; 43: 1193-1195.

[16] F. Poitiers, T. Bouaouiche, M. Machmoum. Advanced control of a doubly-fed induction generator for wind energy conversion. Electric Power Systems Research. 2009; 79: 1085-1096.

[17] Cardenas, R, Pena, R, Perez, M, Clare, J, Asher, G, Wheeler, P. Power smoothing using a flywheel driven by a switched reluctance machine. IEEE Trans. Ind. Electron. 2006; 53(4): 1086-1093.

[18] Muljadi, E, Butterfield, CP. Pitch-controlled variable-speed wind turbine generation. IEEE Trans. Ind. Appl. 2001; 37(1): 240-246.

[19] Wei, Q, Wei, Z, Aller, JM, Harley, RG. Wind speed estimation based sensorless output maximization control for a wind turbine driving a DFIG. IEEE Trans. Power Electron. 2008; 23(3): 1156-1169.

[20] Sharma, S, Singh, B. Control of permanent magnet synchronous generator-based stand-alone wind energy conversion system. IET Power Electron. 2012; 5(8): 1519-1526.

[21] Kazmi, SMR, Goto, H, Hai-Jiao, G, Ichinokura, O. A Novel algorithm for fast and efficient speedsensorless maximum power point tracking in wind energy conversion systems. IEEE Trans. Ind. Electron. 2011; 58(1): 29-36.

[22] Mathiesen, BV, Lund, $\mathrm{H}$. Comparative analyses of seven technologies to facilitate the integration of fluctuating renewable energy sources. IET Renew. Power Gener. 2009; 3(2): 190-204.

[23] Takahashi, R, Kinoshita, H, Murata, T, et al. Output power smoothing and hydrogen production by using variable speed wind generators. IEEE Trans. Ind. Electron. 2010; 57(2): 485-493.

[24] Bragard, M, Soltau, N, Thomas, S, De Doncker, RW. The balance of renewable sources and user demands in grids: power electronics for modular battery energy storage systems. IEEE Trans. Power Electron. 2010; 25(12): 3049-3056.

[25] Bhuiyan, FA, Yazdani, A. Reliability assessment of a wind-power system with integrated energy storage. IET Renew. Power Gener. 2010; 4(3): 211-220.

[26] Sen, PC, Ma, KHJ. Constant torque operation of induction motor using chopper in rotor circuit. IEEE Trans. Ind. Appl. 1978; 14(5): 1226-1229.

[27] Geng, H, Yang, G. Robust pitch controller for output power leveling of variable-speed variable-pitch wind turbine generator systems. IET Renew. Power Gener. 2009; 3(2): 168-179. 
[28] Astrom, KJ, Hagglund, T. PID controllers: theory, design and tuning. Instrument Society of America, Research Triangle Park, NC. 1995.

[29] Lin, W, Hong, C. A new elman neural network-based control algorithm for adjustable-pitch variablespeed wind-energy conversion systems. IEEE Trans. Power Electron. 2011; 26(2): 473-481.

[30] Belkacem, Belabbas, et al. Hybrid fuzzy sliding mode control of a DFIG integrated into the network. International Journal of Power Electronics and Drive Systems (IJPEDS). 2013; 3(4): 351-364. 